\title{
A POPULAÇÃO BRASILEIRA: TRABALHAR E SOBREVIVER
}

Rosa Ester Rossini*

Desde os primeiros dados populacionais brasileiros há a revelação de crescimento acentuado da população. De uma população de 9.930 .000 pessoas em 1872 , atinge-se em pouco mais de um século o contingente de
146.155.000 pessoas em 1991 (Figura: Brasil - População-Censos de 1872 a 1991).

EVOLUÇÃO DA POPULAÇÃO BRASILEIRA - 1872-1980

\begin{tabular}{|lrl|}
\hline CENSOS & POPULAÇÃO POR 1000 & $($ EM \%) \\
\hline 1872 & 9.930 & 2,01 \\
1890 & 14.334 & 2,42 \\
1900 & 18.200 & 2,12 \\
1920 & 27.500 & 2,05 \\
1940 & 41.236 & 2,38 \\
1950 & 51.944 & 2,99 \\
1960 & 70.119 & 2,89 \\
1970 & 93.139 & 2,48 \\
1980 & 119.099 & 1,89 \\
1991 & 146.155 & - \\
\hline
\end{tabular}

Fonte: Censos Demográficos do Brasil

Do final do século até o início da década de 40 o crescimento populacional deveu-se em grande parte não só ao crescimento vegetativo, mas à entrada de estrangeiros no país. $\mathrm{Na}$ estruturação do espaço, a agricultura, especialmente do café, aliada à tendência de urbanização foram responsáveis pelo crescimento acelerado da população, especialmente no Centro-Sul do país.

Sintetizando, poder-se-ia dizer que as formas propriamente capitalistas de produção na agricultura e principalmente nas atividades urbano-industriais se localizavam prioritariamente no eixo Rio de Janeiro - São Paulo. O crescimento demográfico alimentado principalmente pelos fluxos migratórios nacionais, concentrando-se espacialmente no Centro-Sul do país, assim como o mercado consumidor, sustentaram a produção necessária de força de trabalho para a fase inicial do desenvolvimento capitalista.

Se de um lado a rápida expansão do mercado atraía estabelecimentos industriais para atender a essa massa de população, ao mesmo tempo em que cresciam as oportunidades de emprego e de geração de riqueza especialmente em São Paulo, de outro lado continuava o fluxo migratório, aumentava o mercado consumidor, etc... a concentração espacial das indústrias produtoras de bens de consumo atraía igualmente indústrias de bens intermediários, promovendo cada vez mais o processo de concentração da riqueza nesta parte do território.

(*) Professora Titular do Departamento de Geografia da Faculdade de Filosofia, Letras e Ciências Humanas/USP 
A expansāo da ocupação do espaço nacional foi se processando a partir desse pólo dinâmico, favorecido pela penetração das estradas que hoje cortam o território, promovendo uma verdadeira integração nacional comandada pelo Sudeste e de forma particular pela metrópole paulistana.

Assim, a partir de 1940, o crescimento populacional, após a diminuição acentuada da imigração. esteve diretamente relacionado com a queda acentuada da mortalidade e manutenção em níveis bastante elevados da fecundidade.

Embora haja um equilíbrio entre o número de homens e mulheres, cerca de $50 \%$ da população brasileira é constituída por jovens com idades inferiores a 20 anos. Na faixa dos 15 aos 49 anos, porém, há $49,4 \%$ de mulheres.

\section{DISTRIBUIÇÃO ESPACIAL DA POPULAÇÃO BRASILEIRA}

As migrações internas poderiam, em boa parte, ser explicadas como um "mecanismo de redistribuição espacial da população que se adapta, em última análise, ao rearranjo espacial das atividades econômicas" (Singer, 1975 p. 33). (Figura: Brasil - Grandes Regiōes - População Urbana - Censos de 1940 a 1991 Tabela: Brasil - Grandes Regiōes - População Urbana - Censos de 1940 a 1991. Figura: Brasil - Taxas Médias de Incremento anual - 1970/1980 - 1980/1991; Tabela: População Residente, por Sexo e Taxa Média Geométrica de Incremento Anual, segundo as Grandes Regióes e Unidades da Federação - 1991. Tabela: Aspectos da Dinâmica Populacional Brasileira 1970-80).

BRASIL

GRANDES REGIŐES

POPULAÇÃO URBANA

CENSOS DE 1940 À 1991

\begin{tabular}{|l|c|c|c|c|}
\hline \multirow{2}{*}{ Grandes Regiöes } & \multicolumn{4}{|c|}{ em percentagem } \\
\cline { 2 - 5 } & 1940 & 1960 & 1980 & 1991 \\
\hline Norte & 27,75 & 37,80 & 51,69 & 57,84 \\
Nordeste & 23,42 & 34,24 & 50,44 & 60,64 \\
Sudeste & 39,42 & 57,36 & 82,79 & $88,01^{*}$ \\
Sul & 27,73 & 37,58 & 62,41 & 74,12 \\
Centro-Oeste & 21,52 & 35,02 & 67,75 & 79,16 \\
BRASIL & 26,35 & 46,30 & 68,86 & 75,47 \\
\hline
\end{tabular}

* Estado de São Paulo - 1991 - 92,79\%

FONTE: FIBGE - Censo Demográfico 
$102 \mathrm{~A}$

\section{BRASIL - POPULACÃO}

Censos de 1872 a 1991

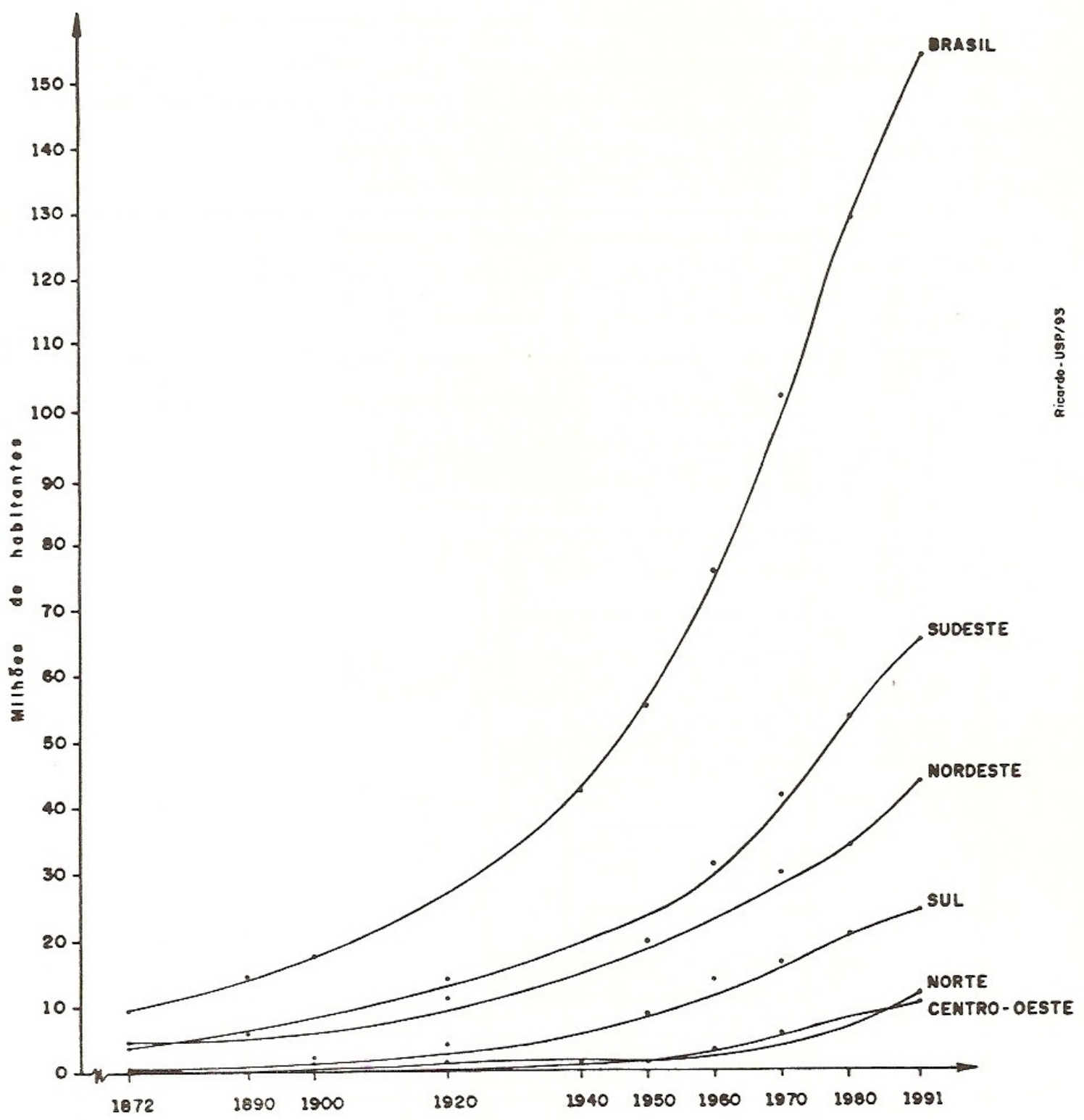

Fonte: FIBGE 


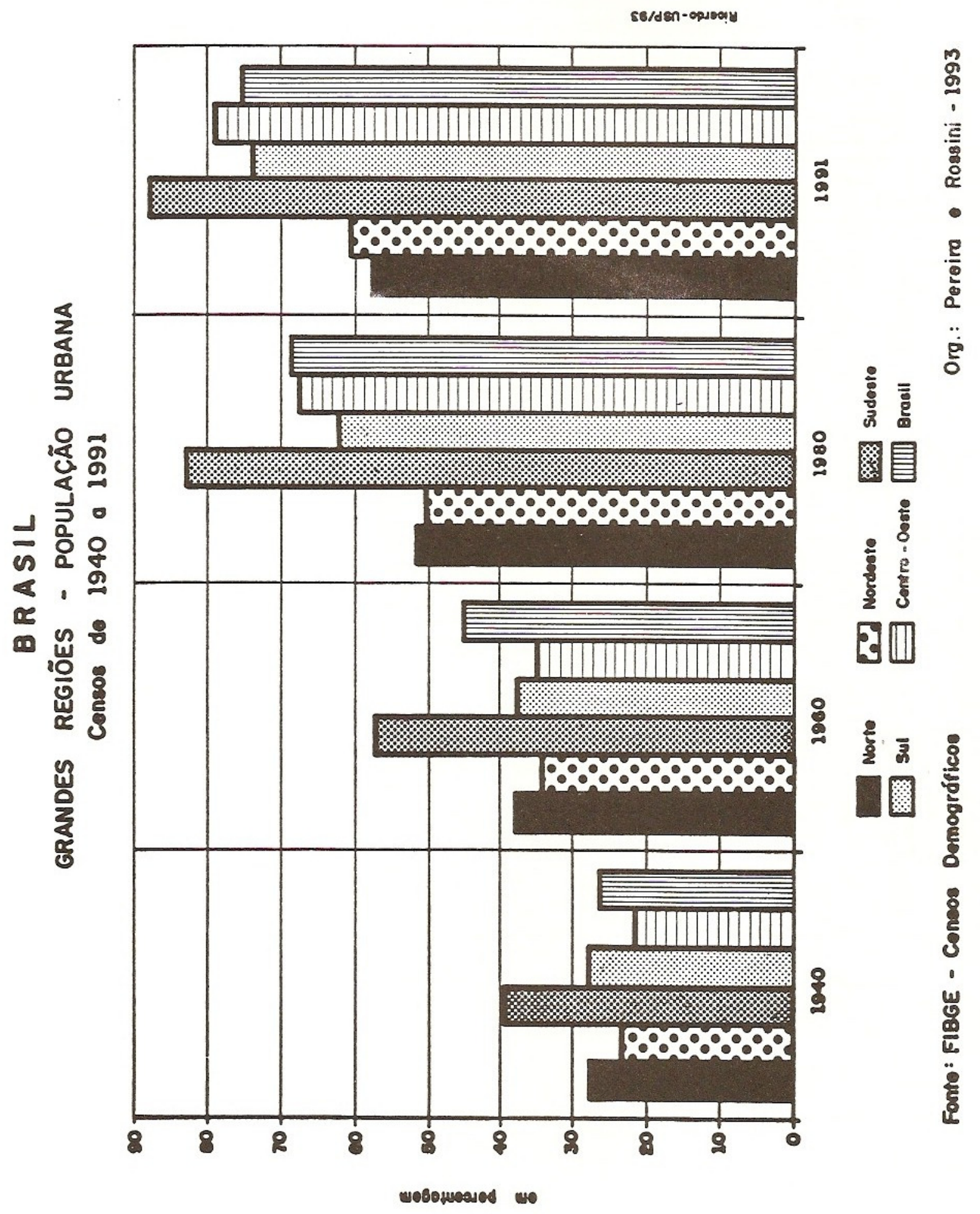


B R A S IL

POPULAÇĀO RESIDENTE, POR SEXO E TAXA MÉDIA GEOMÉTRICA DE INCREMENTO ANUAL, SEGUNDO AS GRANDES REGIŌES E UNIDADES DA FEDERAÇÃO - 1991

\begin{tabular}{|c|c|c|c|c|c|}
\hline \multirow{3}{*}{$\begin{array}{l}\text { Grandes Regiöes } \\
\text { e Unidades } \\
\text { da Federação }\end{array}$} & \multicolumn{3}{|c|}{$\begin{array}{c}\text { POPULAÇÃO RESIDENTE } \\
\text { (1 000 pessoas) } \\
1991 \text { (1) }\end{array}$} & \multirow{2}{*}{\multicolumn{2}{|c|}{$\begin{array}{c}\text { Taxa Média } \\
\text { Geométrica de } \\
\text { Incremento } \\
\text { Anual }\end{array}$}} \\
\hline & \multirow[b]{2}{*}{ Total } & \multirow[b]{2}{*}{ Homens } & \multirow[b]{2}{*}{ Mulheres } & & \\
\hline & & & & $1970 / 80$ & $1980 / 91$ \\
\hline BRASIL & 146155 & 72171 & 73984 & 2,49 & 1,89 \\
\hline NORTE & 10146 & 5178 & 4968 & 5,03 & 3,96 \\
\hline Ronđônia & 1130 & 585 & 545 & 16,00 & 7,87 \\
\hline Acre & 417 & 211 & 206 & 3,45 & 3,01 \\
\hline Amazonas & 2089 & 1076 & 1013 & 4,10 & 3,50 \\
\hline Roraima & 216 & 119 & 97 & 6,06 & 9,55 \\
\hline Pará & 5085 & 2571 & 2513 & 4,64 & 3,72 \\
\hline Amapá & 289 & 145 & 144 & 4,37 & 4,65 \\
\hline Tocantins & 920 & 471 & 449 & - & 2,01 \\
\hline NORDESTE & 42387 & 20727 & 21660 & 2,17 & 1,81 \\
\hline Maranhão & 4922 & 2441 & 2481 & 2,91 & 1,91 \\
\hline Piauí & 2581 & 1261 & 1320 & 2,44 & 1,72 \\
\hline Ceará & 6353 & 3084 & 3269 & 1,96 & 1,68 \\
\hline R. G. do Norte & 2414 & 1178 & 1236 & 2,06 & 2,21 \\
\hline Paraíba & 3201 & 1546 & 1655 & 1,52 & 1,32 \\
\hline Pernambuco & 7110 & 3434 & 3676 & 1,76 & 1,34 \\
\hline Alagoas & 2513 & 1227 & 1286 & 2,28 & 2,18 \\
\hline Sergipe & 1492 & 731 & 762 & 2,36 & 2,48 \\
\hline Bahia & 11802 & 5826 & 5976 & 2,37 & 2,04 \\
\hline SUDESTE & 62121 & 30581 & 31540 & 2,65 & 1,68 \\
\hline Minas Gerais & 15746 & 7801 & 7945 & 1,54 & 1,49 \\
\hline Espírito Santo & 2598 & 1297 & 1301 & 2,36 & 2,30 \\
\hline Rio de Janeiro & 12584 & 6065 & 6519 & 2,31 & 0,99 \\
\hline São Paulo & 31193 & 15419 & 15774 & 3,49 & 2,02 \\
\hline SUL & 22080 & 10957 & 11123 & 1,44 & 1,36 \\
\hline Paraná & 8416 & 4194 & 4222 & 0,97 & 0,90 \\
\hline Santa Catarina & 4536 & 2273 & 2264 & 2,27 & 2,05 \\
\hline R. G. do Sul & 9128 & 4491 & 4637 & 1,56 & 1,47 \\
\hline CENTRO-OESTE & 9420 & 4728 & 4692 & 4,05 & 3,00 \\
\hline M. Grosso do Sul & 1778 & 898 & 880 & 3,20 & 2,40 \\
\hline Mato Grosso & 2021 & 1045 & 975 & 6,62 & 5,35 \\
\hline Goiás & 4025 & 2018 & 2007 & 2,78 & 2,34 \\
\hline Distrito Federal & 1596 & 766 & 830 & 8,13 & 2,81 \\
\hline
\end{tabular}

FONTE:IBGE, Diretoria de Pesquisa, Departamento de População

NOTA - As diferenças apresentadas entre soma de parcelas e totais são provenientes de arredondamento de dados.

(1) Resultados preliminares. 
Tabela

Aspectos da Dinâmica Populacional Brasileira 1970-80

\begin{tabular}{|c|c|c|c|c|c|c|c|c|}
\hline $\begin{array}{l}\text { REGIÃO } \\
\text { E } \\
\text { ESTADO }\end{array}$ & $\begin{array}{c}\text { População } \\
\text { Residente } \\
1970\end{array}$ & $\begin{array}{c}\text { População } \\
\text { Residente } \\
1980\end{array}$ & $\begin{array}{c}\text { Diferença } \\
\text { Absoluta } \\
1970-80\end{array}$ & $\begin{array}{l}\text { Popul } \\
\text { Resid. } \\
1970(\%)\end{array}$ & $\begin{array}{l}\text { Popul. } \\
\text { Resid. } \\
\text { 1980(\%) }\end{array}$ & $\begin{array}{l}\text { No Aum. } \\
\text { Total } \\
1970-80\end{array}$ & $\begin{array}{l}\text { Tx.Cr } \\
\text { Anual } \\
70-80\end{array}$ & $\begin{array}{c}\text { Migração } \\
\text { Líquida } \\
1970-80\end{array}$ \\
\hline NORTE & 3.602 .171 & 5.866 .673 & 2.264 .502 & 3,86 & 4,03 & 8,77 & 5,00 & 915.120 \\
\hline Rondônia & 113.659 & 492.744 & 379.085 & 0,12 & 0,41 & 1,46 & 15,80 & 336.508 \\
\hline Acre & 216.200 & 301.628 & 85.428 & 0,23 & 0,25 & 0,33 & 3,39 & 4.439 \\
\hline Amazonas & 955.394 & 1.406 .354 & 450.960 & 1,02 & 1,18 & 1,75 & 3,94 & 93.067 \\
\hline Roraima & 40.915 & 79.078 & 38.163 & 0,04 & 0,07 & 0,15 & 6,81 & 22.836 \\
\hline Pará & 2.161 .316 & 3.411 .235 & 1.249 .919 & 2,32 & 2,87 & 4,84 & 4,67 & 440.285 \\
\hline Amapá & 114.687 & 175.634 & 60.947 & 0,12 & 0,13 & 0,23 & 4,35 & 17.985 \\
\hline NORDESTE & 28.150 .078 & 34.855 .745 & 6.705 .667 & 30,20 & 29,28 & 25,98 & 2,16 & - $\quad 2.218 .645$ \\
\hline Maranhão & 2.997 .576 & 4.002 .679 & 1.005 .103 & 3,22 & 3,36 & 3,89 & 2,93 & 100.393 \\
\hline Piauí & 1.680 .964 & 2.140 .064 & 459.100 &, 80 & 1,80 & 1,78 & 2,44 & 48.238 \\
\hline Ceará & 4.366 .970 & 5.293 .725 & 926.755 & 4,68 & 4,45 & 3,59 & 1,94 & 424.57 \\
\hline Rio Gde do Norte & 1.552 .158 & 1.899 .725 & 347.567 & 1,67 & 1,60 & 1,35 & 2,04 & 132.738 \\
\hline Paraiba & 2.384 .615 & 2.772 .571 & 387.956 & 2,56 & 2,33 & 1,50 & 1,52 & 349.948 \\
\hline Pernambuco & 5.166 .554 & 6.145 .124 & 978.570 & 5,54 & 5,16 & 3,79 & 1,75 & 620.187 \\
\hline Alagoas & 1.589 .605 & 1.987 .673 & 398.068 & 1,71 & 1,67 & 1,54 & 2,26 & 93.825 \\
\hline Fdo. de Noronha & 1.239 & 1.266 & 27 & - & - & 0,00 & 0,22 & 393 \\
\hline Sergipe & 901.618 & 1.142 .368 & 240.750 & 0,97 & 0,96 & 0,93 & 2,39 & 64.955 \\
\hline Bahia & 7.508 .779 & 9.470 .550 & 961.771 & 8,06 & 7,96 & 7,60 & 2,35 & 584.178 \\
\hline SUDESTE & 39.872 .625 & 51.727 .924 & 11.855 .299 & 42,77 & 43,46 & 45,93 & 2,64 & 2.546 .164 \\
\hline Minas Gerais & 11.497 .574 & 13.382 .904 & 1.885 .330 & 12,33 & 11,24 & 7,30 & 1,53 & - 1.643 .223 \\
\hline Espírito Santo & 1.600 .305 & .023 .752 & 423.447 & 1,72 & 1,70 & 1,64 & 2,38 & - $\quad 67.680$ \\
\hline Rio de Janeiro & 8.998 .857 & 11.297 .962 & 2.299 .105 & 9,65 & 9,49 & 8,91 & 2,30 & 717.334 \\
\hline São Paulo & 17.775 .889 & 25.023 .306 & 7.247 .417 & 19,07 & 21,02 & 28,08 & 3,48 & 3.539 .739 \\
\hline SUL & 16.510 .485 & 19.022 .590 & 2.512 .105 & 17,71 & 15,98 & 9,73 & 1,43 & - $\quad .978 .685$ \\
\hline Paraná & 6.936 .743 & 7.617 .292 & 680.549 & 7,44 & 6,40 & 2,64 & 0,94 & - 1.572 .662 \\
\hline Santa Catarina & 2.903 .360 & 3.628 .761 & 725.379 & 3,11 & 3,05 & 2,81 & 2,26 & 46.827 \\
\hline Rio Grande do Sul & 6.670 .382 & 7.776 .537 & 1.106 .155 & 7,16 & 6,53 & 4,29 & 1,55 & 452.850 \\
\hline CENTRO-OESTE & 5.079 .952 & 7.551 .668 & 2.471 .716 & 5,45 & 6,34 & 9,58 & 4,04 & 736.046 \\
\hline Mto Grosso do Sul & 909.452 & 1.368 .803 & 369.351 & 1,07 & 1,15 & 1,43 & 3,19 & 27.868 \\
\hline Mato Grosso & 601.042 & 1.141 .236 & 540.194 & 0,64 & 0,96 & 2,09 & 6,62 & 334.836 \\
\hline Goiás & 2.941 .107 & 3.864 .881 & 923.774 & 3,16 & 3,25 & 3,58 & 2,77 & 81.116 \\
\hline Distrito Federal & 538.351 & 1.176 .748 & 638.397 & 0,58 & 0,99 & 2,47 & 8,13 & 454.458 \\
\hline BRASIL & 93.215 .311 & 119.024 .600 & 25.809 .289 & $100,00 \%$ & $100,00 \%$ & $100,00 \%$ & 2,47 & +-6.136 .575 \\
\hline
\end{tabular}

Fonte: Resultados Preliminares do Censo 1980 - FIBGE

In Martine, G. 1981 - Notas sobre os resultados prelimiares do Censo Demográfico de 1980 (mimeo)

Para melhor entendimento da questão migratória é conveniente fazer um rápido apanhado da dinâmica do movimento do início do século e, de forma especial, a partir de 1940 , do ponto de vista da composição interregional. Sumarizando, também, idéias de Graham e Holanda Filho (1980), temos:

- o Rio de Janeiro, São Paulo e Estados do Sul predominam, nos anos 30, como as principais áreas de imigração. Minas Gerais e Estados do Nordeste (com exceção da Paraíba, Rio Grande do Norte, Ceará, Piauí, Maranhão) apresentam significativa emigração.

- na década de 40 esta situação continuou, com intensidade no ritmo de emigração para todo o Nordeste e Minas Gerais, em direção especialmente a Săo Paulo, Rio de Janeiro e Estados do Sul do país. Paraná assumiu a liderança de recebimento de contingentes em função da cultura do café na orientação da migração rural-rural. 
104 A

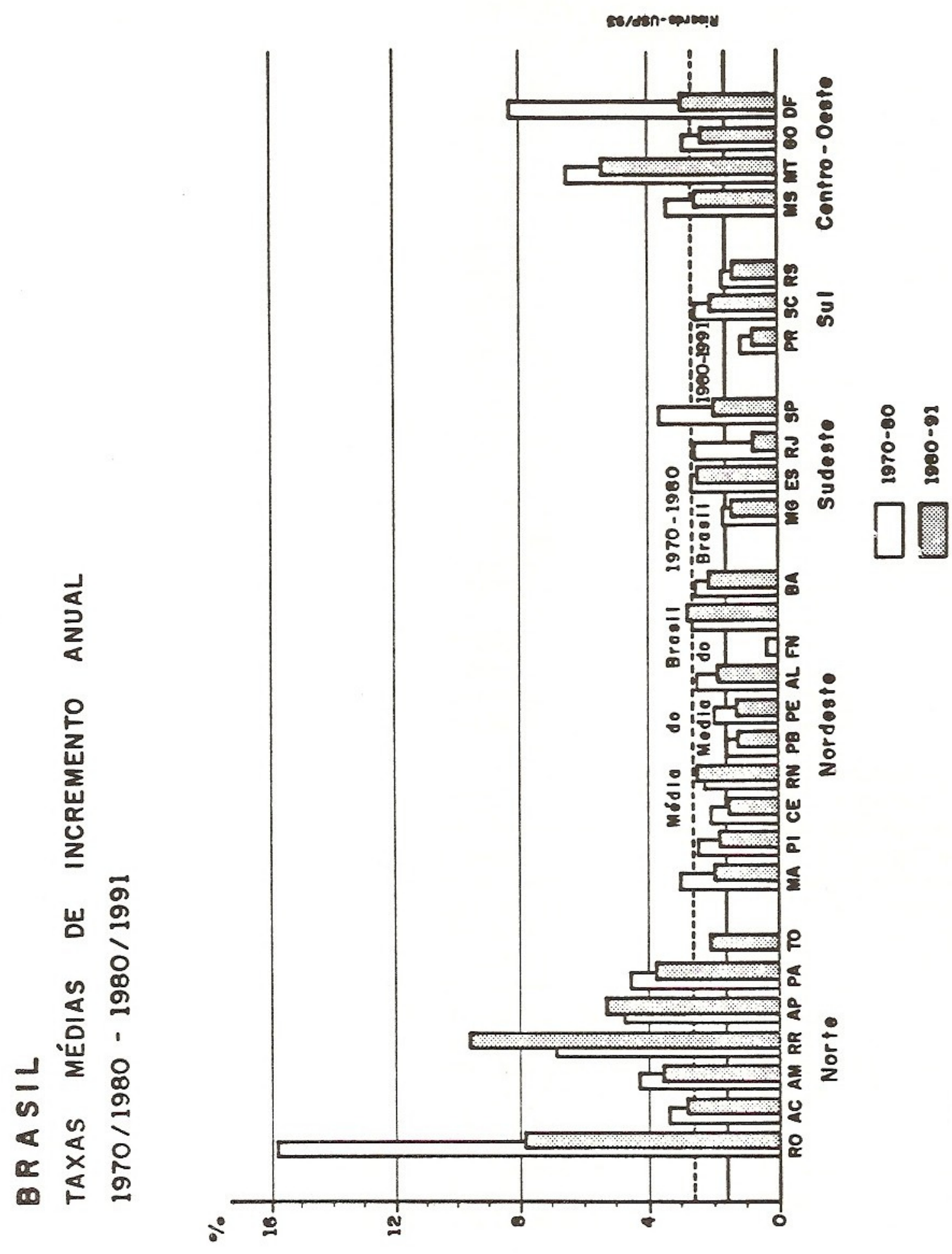

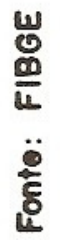


- nos anos 50, registrou-se o maior incremento de fluxos migratórios já registrados no país. Novamente os Estados do Nordeste e Minas Gerais foram os maiores fornecedores de mão-de-obra para São Paulo e Paraná. Surge um novo ator de recebimento de mão-de-obra Goiás - dada a expansão da fronteira agrícola e a construção da capital federal. O programa de Metas do Governo Kubitschek, além de provocar uma grande migração para o Planalto Central, com a construção de Brasília e conseqüente criação de empregos em todos os setores, acelerou também a migração através do processo de industrialização com base na indústria automobilística. Começa a construção de novas estradas, favorecendo a ligação Norte-Sul do país (Andrade, 1982).

- a grande inflexão na tendência histórica dos movimentos migratórios ocorre na década de 60 , quando o Nordeste passou a contribuir com um número relativamente menor de contingentes de modo especial para o Rio de Janeiro, aumentando, porém, em direção a São Paulo. Os movimentos de saída de Minas e Espírito Santo se intensificaram. A queda do movimento para o Paraná começou a se tornar evidente. Goiás e Mato Grosso, as novas frentes de expansão, passaram a ser o grande alvo migratório. Crescem as migrações campocidade aceleradas pela intensificação da penetração das relaçōes capitalistas de produção no campo, complementadas pela política de erradicação dos cafezais pouco produtivos e culminando obviamente com a aplicação da Legislação Trabalhista para o homem do campo. Continuam as políticas de construção de estradas rasgando o país em todos os sentidos. A urbanização se acelera (Andrade, 1982, Taschner e Bogus, 1984, 1986).

- a década de 70 denota uma nova orientação na direção das migrações. A Amazônia no seu conjunto, sobretudo Rondônia, se transforma na área de grande recebimento de pessoas de todo o país; de forma mais expressiva, daquelas oriundas notadamente dos Estados do Paraná, de Santa Catarina e Rio Grande do Sul e até mesmo de Goiás, São Paulo e do Nordeste em geral. Mesmo guardando um forte dinamismo econômico, pois a atividade industrial é hoje bastante relevante na metrópole mineira de Belo Horizonte, o Estado de Minas Gerais continua sendo o maior fornecedor de força de trabalho para todas as áreas onde a reprodução do capital tem sido, naquele momento, significativa. Dada a proximidade com São Paulo, regra geral, os maiores contingentes se encaminham para ele.

O Estado de São Paulo, em todos os momentos, é o grande recebedor de mão-de-obra, apesar de toda a crise pela qual passa o país, enfrentando também a metrópole essas dificuldades. O polo econômico do país, em função de sua atividade industrial, vê suas cifras referentes ao desemprego assumir altíssimas taxas. $\mathrm{O}$ subemprego prolifera, a mendicância e a prostituição aumentam. Proporcionalmente, os asssaltos a bancos, a residências, a casas comerciais se intensificam. $O$ termômetro da crise aparece de forma clara quando supermercados são saqueados, principalmente nas áreas metropolitanas do país e os quebra-quebras em São Paulo, Rio de Janeiro e Salvador se tornam freqüentes. Cresceram, também, as ocupaçōes de terras urbanas e rurais (Rossini, 1987).

Apesar das dificuldades apresentadas, o Estado de São Paulo continua sendo a área onde a reprodução do capital se faz de forma bastante intensa. Cerca de 2.600 .000 pessoas, na década de 70/80, oriundas de outros Estados, migraram para São Paulo e cerca de 200.000 partiram, na sua maioria, à procura de trabalho nas frentes de expansão ou como elementos altamente especializados para atender as áreas urbanas ou rurais com implantação de tecnologia sofisticada.

"As crescentes tensões sociais na Amazônia estão diretamente relacionadas com a natureza dos movimentos populacionais produzidos pela estrutura fundiária brasileira. Pode-se distinguir, no país, três grandes correntes migratórias, duas das quais orientadas para a região amazônica. Uma delas é a já antiga e conhecida corrente que leva trabalhadores do Nordeste para o Sudeste do país,... Do Nordeste, particularmente do Ceará, do Piauí e do Maranhão, sai um outro fluxo em direção ao Norte e ao Centro-Oeste, o que basicamente quer dizer Amazônia Legal. Uma outra grande corrente migratória, mais recente, é a que se dirige do Rio Grande do Sul e do Paraná para o Mato Grosso e Rondônia (Martins, 1980)

Assim sendo, percebe-se que a Amazônia - Amazônia Legal - se constitui, praticamente a partir de 60 , na última fronteira do país. $\mathrm{O}$ recente movimento de expansão do capital monopolista ocorrido na região sob a 
tutela do Estado e, principalmente, a valorização da grande propriedade tem contribuído para a transformação da área como reserva de valor. A melhoria da infraestrutura e o favorecimento às empresas através dos incentivos fiscais permitiria, de um lado, a ocupação através do desenvolvimento da pecuária de corte e, de outro lado, propiciaria um maior conhecimento dos recursos naturais.

Progressivamente, a Amazônia se transforma, através da intervenção do Estado, em um espaço de grande interesse do capital. Antes da década de 60, no entanto, ela já vinha sendo ocupada por massa populacional que, face à distorcida estrutura fundiária do país, é constantemente empurrada pelo capital para as áreas de fronteira num sucessivo processo de migrações.

Para os homens sem terra, o Estado anunciava a perspectiva de um "lugar ao sol". O principal eixo de fixação seria ao longo da Rodovia Transamazônica. Havia, porém, uma distância muito grande entre o discurso do Estado e a sua execução concreta. Apenas $10 \%$ das famílias propostas no projeto inicial foram atendidas.

Os fluxos migratórios para a Amazônia se intensificaram e, ao invés de diminuir as tensões sociais rurais, acabaram por aguçá-las, pois os grandes projetos agropecuários, baseados na grande propriedade, com tecnologia sofisticada, se avolumaram e os pequenos produtores, posseiros e índios perderam paulatinamente espaço. $\mathrm{O}$ vai-e-vem da migração continua e os limites do Estado são transpostos como por exemplo em direção à Bolívia e Peru (Andrade, 1982, p. 195-200).

O que tem ocorrido na Amazônia é a formação de grandes reservas de mão-de-obra, a subordinação do pequeno produtor aos interesses do grande capital, conseqüentemente da grande empresa, permitindo a estas a apropriação dos benefícios da produção sem assumir seus riscos.

É importante ressaltar que, se para os primeiros migrantes foi possível adquirir terra com áreas bem maiores àquelas que possuíam ou que poderiam comprar em outras áreas do território, para aqueles que chegam mais tarde isto passa a ser um sonho, pois o trabalho incorporado à terra pelos pioneiros é também fator que determina sua crescente e acelerada valorização (Jatene, 1983). Intensifica-se a penetração dos capitais paulistas e internacionais. A política de incentivos fiscais corrobora para isso, acelerando essas iniciativas na Amazônia, no Nordeste, etc.

No conjunto, destaca-se a década 70/80 como marcada por uma acentuada tendência concentradora nas áreas mais dinâmicas e coincidentemente as mais densamente povoadas do país. Destaca-se, também, o papel das áreas metropolitanas no conjunto do movimento migratório. Deve-se ter em mente que a Amazônia, no seu conjunto, teve crescimento percentual da população bastante grande.

Embora o Estado de São Paulo tenha crescido a uma taxa ( $3,48 \%$ ao ano) pouco superior à média nacional $(2,47 \%$ ao ano), $28 \%$ do aumento total da população se dirigiu para ele e $46 \%$ para a região Sudeste, na qual ele se insere.

Apesar de as taxas de crescimento no Nordeste terem sido inferiores à média nacional em oito dos nove Estados, sua contribuição, entretanto, foi de $26 \%$ do total do aumento da população. $O$ Maranhão foi o único Estado a apresentar saldo positivo, por se tratar de Estado contíguo à Amazônia e guardar algumas características de área de fronteira agrícola e ter sido também alvo dos especuladores e de projetos governamentais (Rodovia Transamazônica). Os Estados da Bahia, Pernambuco e Paraíba foram os mais afetados pela emigração. O Nordeste, no seu conjunto, "teria perdido, segundo estimativas, um saldo de 2,2 milhões de migrantes. Apesar de ser uma quantia evidentemente substantiva, ela representa uma emigração, em termos proporcionais, bastante menor que a sofrida por Minas ou Paraná" (Martine, 1981).

Os fluxos migratórios dirigidos tanto pelo Estado como por companhias particulares não foram suficientes para diminuir as pressões sociais existentes no país. Embora o número de pessoas que se dirigiu para a Região Norte e Centro-Oeste e, em especial, Rondônia, Pará e Roraima, tenha sido significativo tanto numericamente quanto percentualmente, em função tanto da construção de novos eixos de circulação como pela expansão da fronteira agrícola, fica muito aquém do contingente que se encaminhou para o Sudeste, no seu conjunto. É de se ressaltar, entretanto, que Rondônia, na década, teve uma taxa de acréscimo médio anual de $15,80 \%$, seguido de Roraima com $6,81 \%$, igualmente 
BRASIL

TENDÊNCIA DAS MIGRACÕES INTERNAS

1988

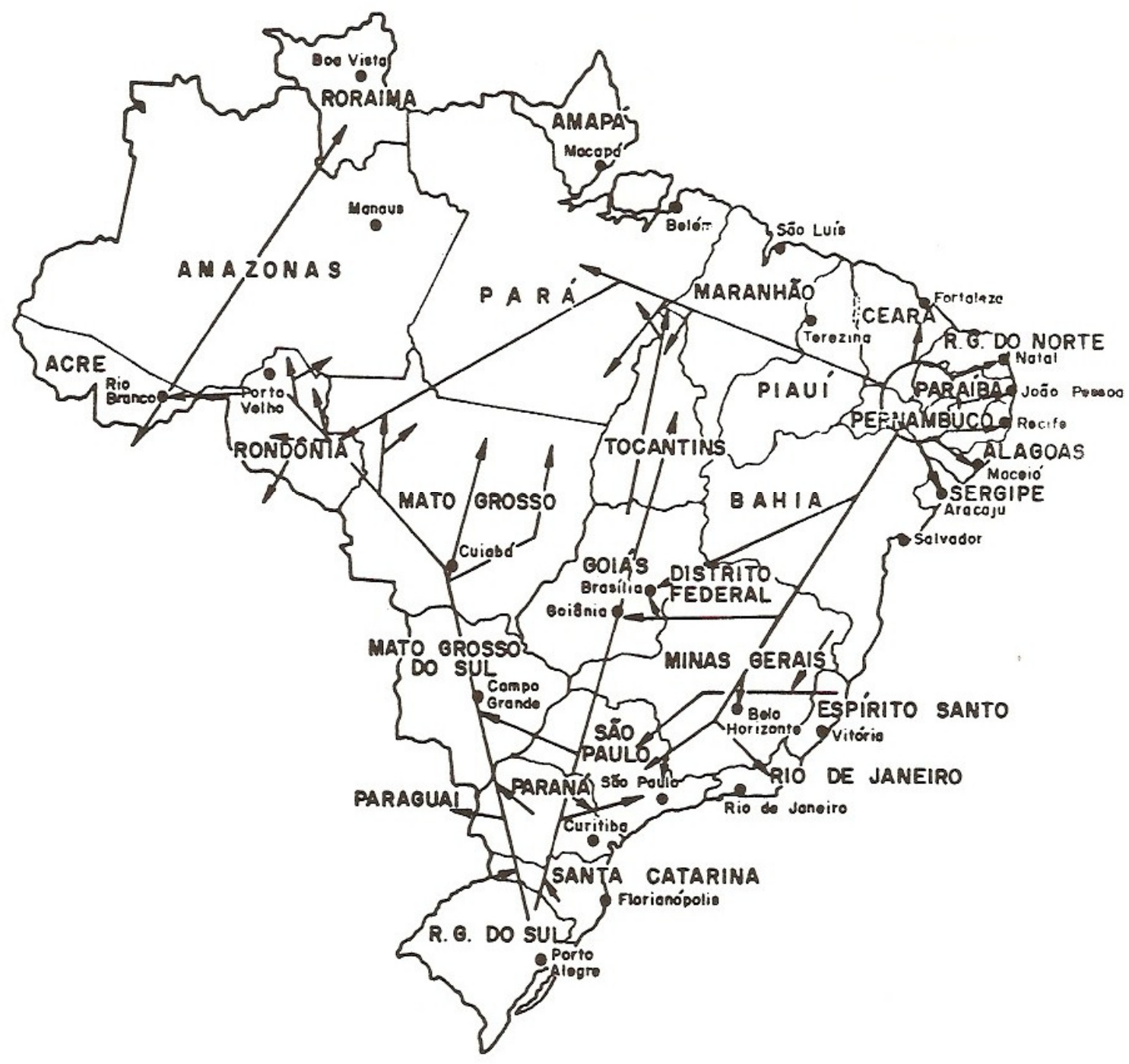

Q $730 \mathrm{Km}$.

Org.: Rosaini, Simielli, Real Ricardo - USP/92 
Mato Grosso com 6,62\% e o Distrito Federal com $8,13 \%$.

Goiás, que desde 1940 vinha apresentando as mesmas características do Paraná quanto ao crescimento, teve perdas líquidas de população, embora tivesse mantido uma taxa de aumento pouco superior à média nacional, devido ao forte crescimento vegetativo.

Paraná, o segundo Estado com maior perda líquida - (1.572.662 pessoas) na década, como se sabe, constituía, desde 1940 até a década de 60, uma área de atração por excelência, dado o dinamismo ligado à implantação da agricultura cafeeira e, na última década (1970/80), conforme já referido, foi o Estado que teve a mais baixa taxa de incremento anual de população do país $(0,94 \%$ ao ano). O Rio Grande do Sul, devido à concentração de terras, ao desenvolvimento de agricultura sofisticada e à saturação populacional das pequenas propriedades - colônias -, vem perdendo o ritmo de crescimento e na última década chegou a ter um saldo negativo de 580 mil pessoas e uma taxa de crescimento médio anual na ordem de 1,55\% (Rossini, 1988).
Reforçando o caráter concentrador dos homens onde se encontra o capital, destaque-se que $43,9 \%$ do crescimento populacional da década de 70 se deveu a nove áreas metropolitanas, mais o Distrito Federal - Belém, Fortaleza, Recife, Salvador, Belo Horizonte, Rio de Janeiro, São Paulo, Curitiba e Porto Alegre. Enquanto o Brasil, como um todo, teve uma taxa de crescimento anual de $2,47 \%$, essas nove áreas metropolitanas e o Distrito Federal tiveram 3,9\% ao ano. Recife e Rio de Janeiro tiveram taxa de crescimento inferior. Destaque-se, ainda, que o aumento absoluto de população foi de quase 2 milhões de pessoas para o Rio de Janeiro. Curitiba, com crescimento um pouco inferior à média das áreas metropolitanas, teve, entretanto, uma taxa de aumento populacional bem superior à média nacional, exatamente por ter atraído, em função dos empreendimentos urbanos e industriais, boa parte da população que saía das áreas principalmente agrícolas do Paraná e mesmo dos pequenos centros urbanos. (Tabela: Dinâmica Populacional das Áreas Metropolitanas Brasileiras. 1970 - 80; Figura: Brasil - Tendência das Migrações Internas - 1988; Tabela: População das Regiōes Metropolitanas e do Distrito Federal - 1991).

Tabela

Dinâmica Populacional das Áreas Metropolitanas Brasileiras e do Distrito Federal - 1970 - 80

\begin{tabular}{|c|c|c|c|c|c|c|c|}
\hline $\begin{array}{l}\text { ÁREAS } \\
\text { METROPO- } \\
\text { LITANAS }\end{array}$ & $\begin{array}{c}\text { População } \\
1970\end{array}$ & $\begin{array}{c}\text { População } \\
1980\end{array}$ & $\begin{array}{l}\text { Aumento } \\
\text { Absoluto }\end{array}$ & $\begin{array}{l}\text { \%o sobre } \\
\text { Aumento } \\
\text { País }\end{array}$ & $\begin{array}{l}\text { Taxa } \\
\text { Cresc } \\
\text { Anual }\end{array}$ & $\begin{array}{l}\text { Migração } \\
\text { Líquida }\end{array}$ & $\begin{array}{r}\text { Crescimento } \\
\text { Vegetativo }\end{array}$ \\
\hline Belém & 656.351 & 1.000 .357 & 344.006 & 1,33 & 4,30 & +100.128 & 243.878 \\
\hline Fortaleza & 1.038 .041 & 1.581 .457 & 543.416 & 2,11 & 4,30 & +225.200 & 318.216 \\
\hline Recife & 1.792 .688 & 2.346 .196 & 553.508 & 2,14 & 2,73 & $+\quad 3.952$ & 549.556 \\
\hline Salvador & 1.148 .828 & 1.766 .075 & 617.247 & 2,39 & 4,39 & +231.117 & 386.130 \\
\hline Belo Horizonte & 1.605 .663 & 2.534 .576 & 928.913 & 3,60 & 4,67 & +440.772 & 488.141 \\
\hline Rio de Janeiro & 7.082 .404 & 9.018 .961 & 1.936 .557 & 7,50 & 2,47 & +710.026 & 1.226 .531 \\
\hline São Paulo & 8.137 .401 & 12.578 .045 & 4.440 .644 & 17,21 & 4,45 & +2.765 .072 & 1.675 .572 \\
\hline Curitiba & 820.766 & 1.441 .743 & 620.977 & 2,41 & 5,80 & +386.849 & 234.128 \\
\hline Porto Alegre & 1.531 .164 & 2.232 .370 & 701.202 & 2,72 & 3,84 & +399.390 & 301.812 \\
\hline Distrito Federal & 538.351 & 1.176 .748 & 638.397 & 2,47 & 8,13 & +454.458 & 183.939 \\
\hline TOTAL & 24.351 .657 & 35.676 .528 & 11.324 .867 & $43,88 \%$ & 3,89 & +5.716 .964 & 5.607 .903 \\
\hline BRASIL & 93.215 .311 & 119.024 .600 & 25.809 .289 & $100,00 \%$ & 2,47 & - & 25.809 .289 \\
\hline
\end{tabular}

Fonte: Resultados Preliminares do Censo 1980 - FIBGE

In Martine, G. 1981 - Notas sobre os resultados preliminares do Censo Demográfico de 1980 (mimeo) 
O Distrito Federal, em relação às áreas metropolitanas, foi o que apresentou a maior taxa de crescimento $-8,13 \%$ ao ano. As explicaçöes desse incremento residem tanto no fato de que a área continua sendo bastante dinâmica como no fato de sediar a Capital Federal.

Surpreendente, em todos os sentidos, foi o crescimento numérico tanto da área metropolitana de São
Paulo como da própria cidade. Em 1980, das 11.300 .000 pessoas a mais existentes em relação a 1970, nas áreas metropolitanas, mais o Distrito Federal, São Paulo assumiu a responsabilidade de 4.400 .000 pessoas. As causas já foram expressas no decorrer do trabalho, mas convém recuperar que elas residem muito provavelmente na concentração progressiva de investimentos e atividades econômicas.

\section{B R A S I L \\ POPULAÇÃO DAS REGIÕES METROPOLITANAS \\ E DO DISTRITO FEDERAL - 1991}

\begin{tabular}{|lr|}
\hline Regiões Metropolitanas & 1991 \\
\hline Belém & 1334460 \\
Fortaleza & 2292524 \\
Recife & 2859469 \\
Salvador & 2472131 \\
Belo Horizonte & 3461905 \\
Rio de Janeiro & 9600528 \\
São Paulo & 15199423 \\
Curitiba & 1975624 \\
Porto Alegre & 3015960 \\
Distrito Federal & 1596274 \\
\hline BRASIL & 146326159 \\
\hline
\end{tabular}

FONTE: FIBGE, Censo Demográfico - 1991 (resultados preliminares)

Merece referência ainda o caso dos migrantes intra-urbanos, fenômeno que ocorre em praticamente todas as cidades, mas que é mais evidente nos grandes centros e que se tem acelerado nos últimos anos, em função das menores oportunidades de trabalho e do próprio rebaixamento dos salários. As favelas e os cortiços deixaram de ser "privilégio" dos desocupados, dos marginais, para se transformarem em local de residência da população trabalhadora, engajada no mercado formal ou informal. Destaca-se ainda o fato de que ambos não mais ocorrem só nos locais mais centrais ou de fácil acesso, mas estendem-se também por toda a periferia. Nesse caso, em função da renda da terra urbana, toda a população de baixa renda é empurrada cada vez mais para a periferia mais remota, sem as mínimas condições de infra-estrutura (Rodrigues, 1988).

No conjunto do território nacional, apesar de o movimento migratório ter sido intenso, o peso representado pela migração internacional foi inexpressivo.

A procissão dos descontentes tem aumentado significativamente. As notícias veiculadas pela imprensa falada e escrita indicam um deslocamento cada vez maior de pessoas à procura de trabalho no Exterior. De Minas Gerais - em especial de Governador Valadares - 
$108 \mathrm{~A}$

BRASIL

NATALIDADE, MORTALIDADE E CRESCIMENTO NATURAL.

$1940-1980$

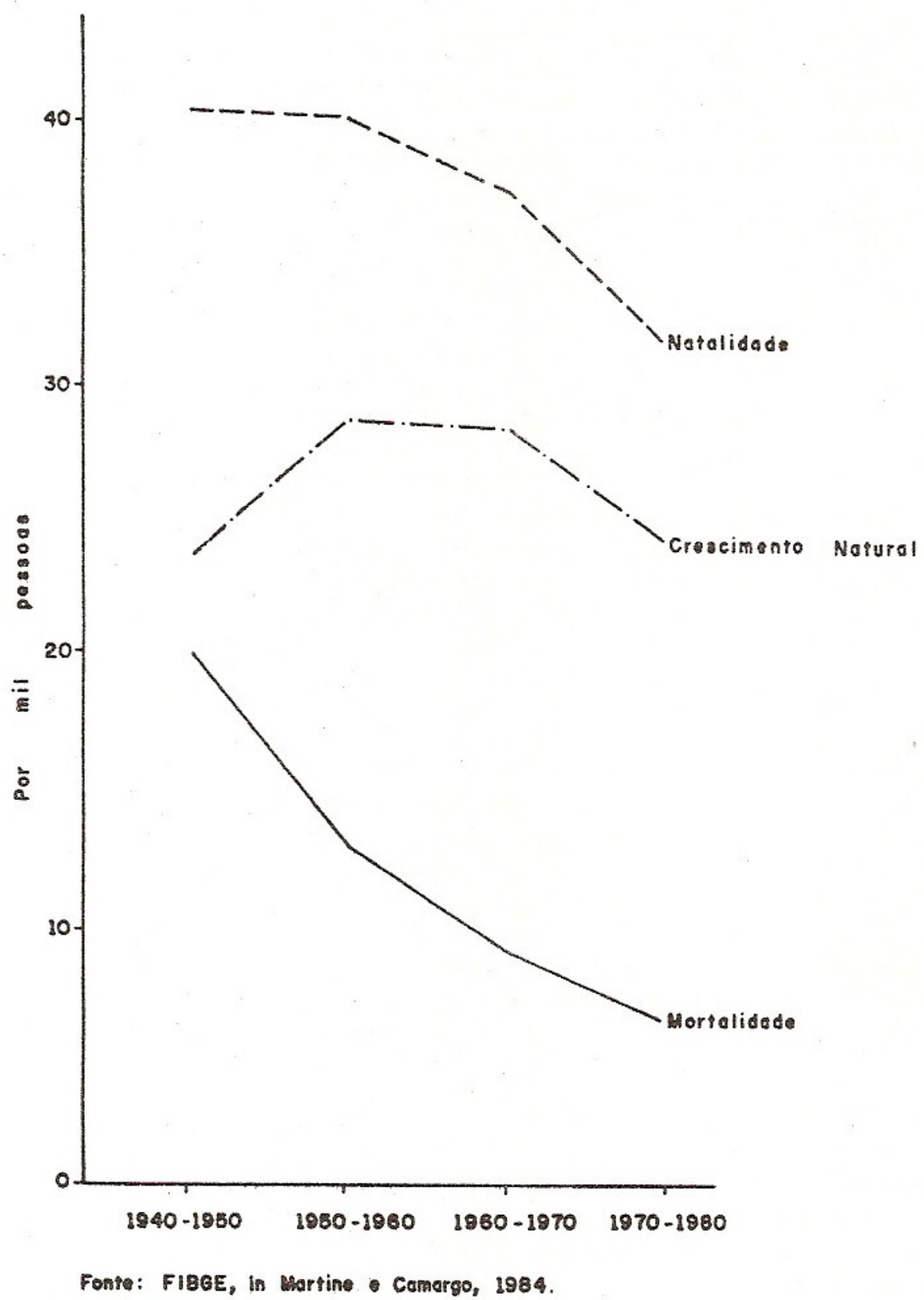

Org.: Rossini, Simielli, Roal

Ricardo - USP/פ2 
tem partido volume significativo de pessoas para os Estados Unidos. Dos Estados do Sudeste o fluxo maior tem sido à Europa. Há predomínio de migrantes com baixa escolaridade e pouca especialização. Muitos, após meses de procura de emprego sem sucesso, forçam a repatriação; outros, mais afortunados, conseguem fazer seu "pé-de-meia" e voltam "ricos" ou fixam residência definitiva no exterior. Os profissionais liberais parecem ter mais sorte em Portugal (dentistas). O volume, embora sem expressão, denota insatisfação em relação à situação geral do país. Conclui-se, portanto, que o aumento populacional, na sua quase totalidade, se deve ao crescimento vegetativo bastante alto de boa parte da população brasileira.

Considerando que o país conheceu um decréscimo no ritmo de crescimento a partir das últimas déca- das e que este foi devido à reversão no comportamento reprodutivo da sociedade brasileira, convém analisar como se procedeu esta dinâmica.

\section{TENDENCIA ATUAL DOS COMPONENTES DO CRESCIMENTO POPULACIONAL}

Só a partir da década de 40 é que o Brasil se equipou melhor, do ponto de vista das informações, para fornecer dados mais precisos a respeito dos componentes de seu crescimento (Figura: Brasil - Natalidade, Mortalidade e Crescimento Natural - 1940 - 1980; Tabela: Brasil - Decomposição da Taxa Média de Crescimento Anual da População - 1940-1980).

Brasil

Decomposição da taxa média de crescimento anual da população 1940-1980

\begin{tabular}{|c|c|c|c|c|c|}
\hline Intervalo & $\begin{array}{c}\text { Taxa Bruta de } \\
\text { Natalidade } \\
(\mathrm{N}) \% \text { o }\end{array}$ & $\begin{array}{c}\text { Taxa Bruta de } \\
\text { Mortalidade } \\
(\mathbf{M}) \% \text { o }\end{array}$ & $\begin{array}{c}\text { Crescimento } \\
\text { Natural } \\
(\mathrm{N}-\mathrm{M}) \% \text { o }\end{array}$ & $\begin{array}{c}\text { Migração } \\
\text { Líquida } \\
\text { (I) \% o }\end{array}$ & $\begin{array}{c}\text { Crescimento } \\
\text { Total } \\
(\mathrm{N}-\mathrm{M}+\mathrm{I}) \% \text { o }\end{array}$ \\
\hline $1940-1950$ & 44,4 & 20,6 & 23,8 & 0,04 & 23,7 \\
$1950-1960$ & 43,3 & 13,4 & 29,0 & 0,09 & 29,9 \\
$1960-1970$ & 37,7 & 9,6 & 28,9 & - & 28,3 \\
$1970-1980$ & 32,1 & 7,2 & 24,9 & - & 24,9 \\
\hline
\end{tabular}

Fonte: IBGE - Diretoria Técnica. Departamento de Estudos de População (DESPO) In: Martine, G. e Camargo, L., Revista Brasileira de Estudos Populacionais. Vol. no 1/2, jan/dez - 1984 p. 102.

\section{Diminuição relativa da Mortalidade.}

A queda acentuada da mortalidade provocou modoficação substancial no resultado do crescimento total da população brasileira, posto que o componente imigratório tem sido irrelevante numérica e relativamente. Não se torna necessário ressaltar que isso se deveu mais ao avanço da medicina etc., do que a melhoria da qualidade de vida e de saúde da população em geral.

A taxa bruta de mortalidade vem descrescendo desde 1870 . Nesta época situava-se em torno de $28 \%$, e antes de 1940 era de $25 \%$ o. Conforme a tabela, na década de 1940 foi de $20,6 \%$ e em $1970-80$ chegou-se a $7,2 \%$ o.

Além dos fatores acima mencionados, que ajudam a justificar a diminuição da mortalidade, há que se ressaltar também a medicina previdenciária, o controle de epidemias e endemias, as vacinaçōes complusórias (sarampo, meningite, catapora), melhoria no atendimento de água tratada, etc., que foram determinantes para a diminuição da mortalidade geral e infantil (Tabela: Bra- 
sil - Evolução da Taxa de Mortalidade Infantil - 19401980).

Continua, porém, sendo alta a mortalidade infantil. Segundo dados de 1975 das Naçōes Unidas para o
Brasil, a cada 1000 nascidos vivos, 109 morrem antes de completar o primeiro ano de idade, enquanto que na América do Norte esta taxa é de 15.

Brasil

Evolução da Taxa de Mortalidade Infantil $1940-1980$

\begin{tabular}{|l|l|r|r|r|r|}
\hline Regiões & 1940 & 1950 & 1960 & 1970 & 1980 \\
\hline Norte & - & 171,6 & 122,0 & 67,1 & 100,0 \\
Nordeste & - & 206,9 & 183,6 & 149,3 & 130,0 \\
Sudeste & - & 99,9 & 67,7 & 83,5 & 67,0 \\
Sul & - & 130,6 & 107,7 & 77,1 & 55,1 \\
Centro-Oeste & - & 126,8 & 104,1 & 80,3 & 85,0 \\
Brasil & $\mathbf{1 6 4 , 0}$ & $\mathbf{1 3 6 , 6}$ & $\mathbf{1 0 5 , 2}$ & $\mathbf{9 2 , 0}$ & $\mathbf{8 7 , 3}$ \\
\hline
\end{tabular}

Fonte: Anuário de Bioestatística (Ministério da Educação e Saúde) 1950/51; Anuário Estatístico do Brasil (IBGE) 1950/1978; Ministério da Saúde - Secretaria de Planejamento - Núcleo de Informática; Secretarias Estaduais de Estatística. In Martine, G. e Camargo, L. 1984.

Para boa parte da população, no caso da população carente, falta a medicina preventiva e curativa, que deixa de ser um direito inalienável do cidadão, para ser privilégio de poucos. Falta de atendimento médico aliada a fome endêmica configuram os fatores principais responsáveis pelos altos riscos de morte, especialmente no primeiro ano de vida.
Conforme já referido, a queda dos índices de mortalidade é devida, fundamentalmente, ao controle das doenças infecciosas e parasitárias (Tabela: Brasil e Estado de São Paulo - Esperança de Vida ao Nascer 1940 - 1980).

TABELA

BRASIL E ESTADO DE SÃO PAULO ESPERANÇA DE VIDA AO NASCER

$1940-1980$

(ANOS DE VIDA)

\begin{tabular}{|lcc|}
\hline ANO & BRASIL & ESTADO DE SÃO PAULO \\
\hline 1940 & 41,53 & 45,37 \\
1950 & 45,51 & 54,20 \\
1960 & 51,54 & 61,21 \\
1970 & 53,46 & 62,64 \\
1980 & 59,09 & 66,67 \\
\hline
\end{tabular}

FONTE: Fundação IBGE

Anuário Estatístico do Brasil, 1982 
$110 \mathrm{~A}$
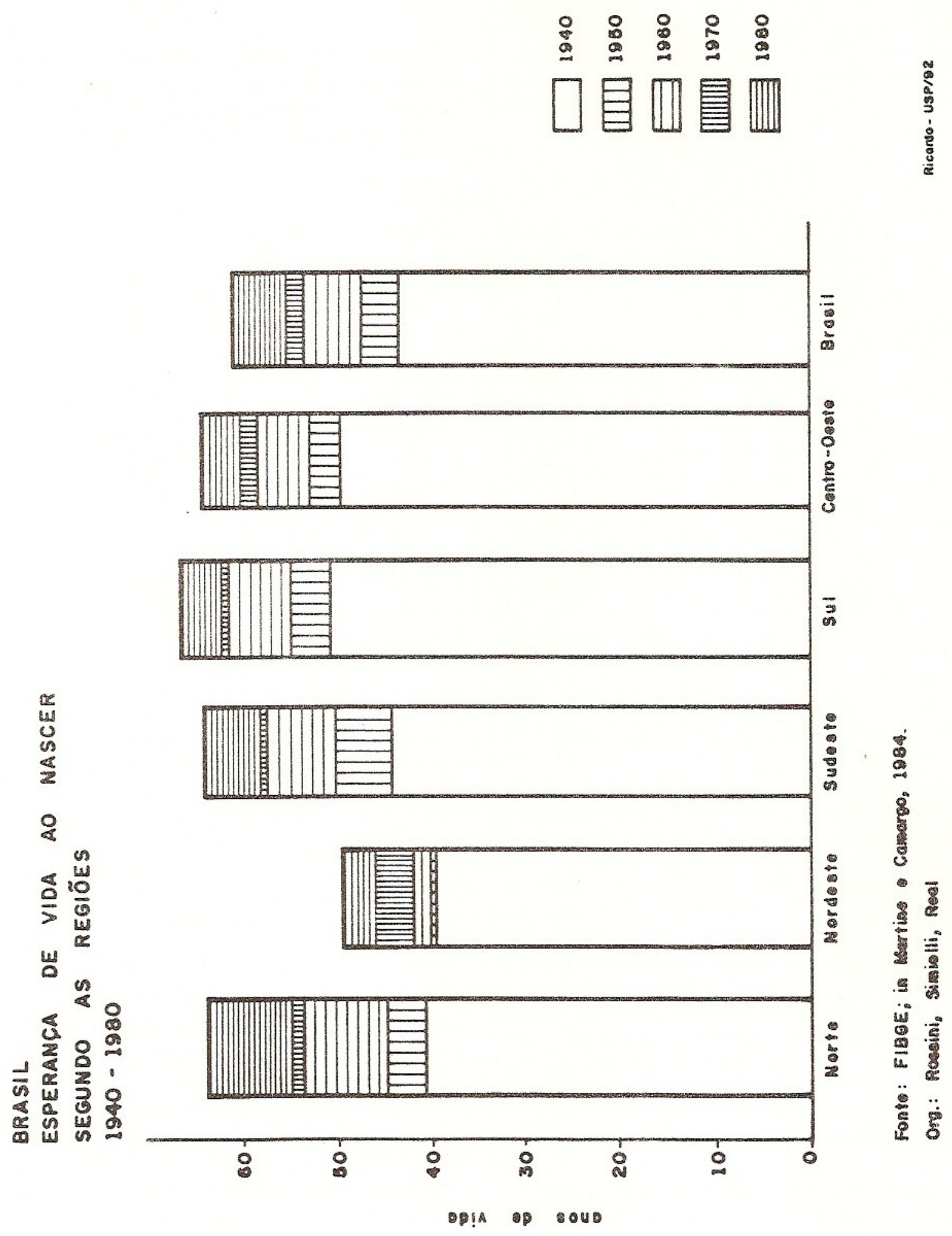


\section{Aumento da esperança de vida}

A esperança de vida do brasileiro, apesar da taxa de mortalidade geral e infantil serem altas e decrescentes, vem aumentando substancialmente. De 1940 para 1980 aumentou em mais de $40 \%$ (41,53 anos e 59,09 anos, respectivamente) (Figura: Brasil - Esperança de Vida ao Nascer, Segundo as Regiões - 1940-1980; Tabela: Brasil - Estimativa da esperança de vida ao nascer para anos anteriores e próximos aos anos censitários 1940-1980).

Brasil

Estimativa da esperança de vida ao nascer para anos anteriores e próximos aos anos censitários $1940-1980$

\begin{tabular}{|l|r|r|r|r|l|}
\hline Regiōes & 1940 & 1950 & 1960 & 1970 & 1980 \\
\hline Norte & 40,70 & 44,87 & 53,56 & 54,74 & 63,61 \\
Nordeste & 38,76 & 8,96 & 1,06 & 45,55 & 49,00 \\
Sudeste & 43,58 & 49,08 & 56,79 & 57,38 & 63,59 \\
Sul & 49,61 & 53,47 & 60,43 & 60,74 & 65,54 \\
Centro-Oeste & 48,13 & 51,19 & 56,91 & 58,91 & 63,09 \\
Brasil & 41,53 & 45,51 & 51,64 & 53,46 & 59,09 \\
\hline
\end{tabular}

Fonte: IBGE - Anuário Estatístico do Brasil, 1982, Diretoria Técnica(DESPO) In Martine, G. e Camargo, L., 1984

A mais expressiva melhoria da esperança de vida ao nascer é encontrada na região Norte do país, área de recente penetração de ocupação e expansão acelerada do capitalismo. Até muito pouco tempo, o acesso para boa parte da área era feito via navegação fluvial ou por avião. Hoje, embora as rodovias cortem muito pouco a área, ela foi bastante integrada ao conjunto nacional e se tornou locus da expansão do capitalismo internacional e nacional.

Nesta última década, foi a área que mais recebeu relativamente contigente nacional, especialmente em Rondônia, fruto da expansão da fronteira agrícola. Se de um lado é área de ocupação por parte do grande capital e mesmo de pequenos proprietários e posseiros, por outro é área dos maiores conflitos de terra e, em especial, envolvendo o índio, que tem paulatinamente perdido terras ou vem sendo dizimado pelo "conquistador".

\section{Diminuição da taxa bruta de natalidade}

A taxa bruta de natalidade, juntamente com a de mortalidade servem como primeira informação para aferir o crescimento populacional.

A taxa de natalidade, $1930-40$, era de $47,2 \%$ o e passa para 32,1\%o em 1970-80.

Esse decréscimo não é específico do caso brasileiro, é um fenômeno mundial. No país, esse comportamento é diferente de uma área para outra. Essa taxa bruta variou de $52,7 \%$ o na Bahia para $30 \%$ o no Rio de Janeiro em 1960-70 (Carvalho, 1974).

\section{Acentuada tendência de queda da Fecundidade}

Dentre as variáveis demográficas, é a fecundidade que mais sensivelmente faz sentir seus efeitos sobre a 
população e é a variação de seu nível que define fundamentalmente a distribuição etária da população. As taxas de fecundidade que medem com maior precisão do que aquelas de natalidade os diferenciais no comporta- mento reprodutivo (Tabela: Brasil e Grandes Regiōes. Taxas de Fecundidade Total, segundo domicílios urbano e rural da população - 1960/70 e 1970/80).

Brasil e Grandes Regióes

Taxas de fecundidade Total, segundo domicílios urbano e rural da população - 1960-70 e 1970-80.

\begin{tabular}{lccc|}
\hline REGIÖES TFT & $\begin{array}{c}1960-1970 \\
(\mathrm{~A})\end{array}$ & $\begin{array}{c}1970-1980 \\
(\mathrm{~B})\end{array}$ & $\mathrm{B} / \mathrm{A}$ \\
\hline TOTAL BRASIL & 5,76 & 4,35 & 0,75 \\
Norte & 8,15 & 6,45 & 0,79 \\
Nordeste & 7,53 & 6,13 & 0,81 \\
Sudeste & 4,56 & 3,45 & 0,75 \\
Sul & 5,42 & 3,63 & 0,66 \\
Centro - Oeste & 6,42 & 4,51 & 0,70 \\
& & & \\
URBANA TOTAL & 4,54 & 3,63 & 0,79 \\
Norte & 6,62 & 5,24 & 0,79 \\
Nordeste & 6,44 & 4,94 & 0,76 \\
Sudeste & 3,83 & 3,17 & 0,83 \\
Sul & 4,06 & 3,63 & 0,89 \\
Centro - Oeste & 5,31 & 4,51 & 0,85 \\
& & & \\
RURAL TOTAL & 7,72 & 6,40 & 0,82 \\
Norte & 9,59 & 8,05 & 0,84 \\
Nordeste & 8,45 & 7,65 & 0,90 \\
Sudeste & 7,14 & 5,46 & 0,76 \\
Sul & 6,86 & 4,55 & 0,66 \\
Centro - Oeste & 7,71 & 5,98 & 0,77 \\
\hline
\end{tabular}

Fonte: IBGE. DESPO in Martine, G. e Camargo, L., 1984

Sem nenhuma exceção, todas as regiões brasileiras, tanto na área rural como na área urbana, sofreram diminuição na taxa de fecundidade.

De modo geral, esses números refletem, com maior ou menor intensidade, os padrões de modernização e as taxas de urbanização. Nas áreas cujo desenvolvimento sócio-econômico e urbano são menores, as taxas de fecundidade são maiores, como no caso do Norte do País, para as duas décadas. O sudeste, onde grande peso pode ser imputado a São Paulo, centro dinâmico do país, apresenta as mais baixas taxas de fecundidade geral, juntamente com os Estados do Sul do País.

O Sudeste urbano experimentou a mais baixa queda no período. Explica-se claramente este fato justamente porque esta área já vinha demonstrando uma tendência à queda, anterior a 1970, justificando, portanto, decréscimos menos substânciais. 
Alguns fatores devem ser levantados para ajudar a explicação dessa queda acentuada da fecundidade no Brasil. Não se pode, entretanto, considerá-los como conclusivos.

A idade média ao casar, em torno dos 23 anos, tem-se mantido relativamente estável nas últimas décadas. Mostra-se bem inferior, entretanto, quando comparada com as dos países mais industrializados.

Mesmo não dispondo de dados sistematizados atuais, pode-se, com toda a segurança, informar que as mulheres que habitam no meio rural têm uniões mais precoses que aquelas residentes nas áreas urbanas e que mais alto índice de escolarização é também fator preponderante para a realização mais tardia dos casamentos.

Assim sendo, a maior possibilidade de acesso à escola, aliada ao maior índice de escolarização, juntamente com o aumento da penetração mais intensa de formas capitalistas de produção naś áreas rurais e urbanas, bem como o aumento da participação da mulher no mercado de trabalho têm retardado tanto para os homens como para as mulheres a idade ao casar. Isto evi- dentemente vai provocar e acelerar esta tendência da queda da fecundidade.

Esta declinante queda da fecundidade, por exemplo, na Região Sudeste do país, pode também estar vinculada a uma interpretaçấo que se baseia nos efeitos das transformações sócio-econômicas características dessa última década. A queda relativa dos salários, a difusão dos valores de consumo, o mais fácil acesso aos métodos anticoncepcionais, a monetarização acentuada das relaçōes sociais em geral levam à maior predisposição à redução da prole.

Embora haja uma diminuição considerável da fecundidade, ela é mais expressiva em relação àquela faixa da população que recebe mais baixos salários, ou melhor, aquela que está no nível da miséria. Para as outras classes de renda, provavelmente devido ao processo de monetarização das relações de trabalho, houve até insignificantes aumentos (Oliveira, 1984); (Tabela: Região Sudeste - Taxa de Fecundidade Total, segundo classes de rendimento familiar per capita e situação do domicilio - 1970/80).

REGLÃO SUDESTE

Taxa de Fecundidade Total, segundo classes de rendimento familiar per capita e situação do domicilio - 1970/1980

\begin{tabular}{|c|c|c|c|c|c|c|c|c|c|c|}
\hline \multirow{2}{*}{$\begin{array}{l}\text { Situaçảo do Domicnlio } \\
\text { e Classes de Rendimen- } \\
\text { to per capita. } \\
\text { (Salário Mínimo) }\end{array}$} & \multicolumn{10}{|c|}{ TAXA DE FECUNDIDADE TOTAL } \\
\hline & \multicolumn{2}{|c|}{$\begin{array}{c}\text { Região Sudeste } \\
1970-1980\end{array}$} & \multicolumn{2}{|c|}{$\begin{array}{c}\text { Minas Gerais } \\
1970-1980\end{array}$} & \multicolumn{2}{|c|}{$\begin{array}{l}\text { Esp. Santo } \\
1970-1980\end{array}$} & \multicolumn{2}{|c|}{$\begin{array}{c}\text { Rio de Janeiro } \\
1970-1980\end{array}$} & \multicolumn{2}{|c|}{$\begin{array}{l}\text { São Paulo } \\
1970-1980\end{array}$} \\
\hline até $1 / 4$ S.M. & & 6,43 & 8,86 & 7,05 & 7,65 & 6,80 & 7,96 & 5,77 & 7,40 & 5,91 \\
\hline $1 / 4$ a $1 / 2$ S.M. & 4,75 & 5,07 & 4,85 & 4,94 & 4,89 & 5,05 & 4,64 & 4,65 & 4,70 & 5,54 \\
\hline $1 / 2$ a 1 S.M. & 3,20 & 3,52 & 2,95 & 3,28 & 2,12 & 3,26 & 3,06 & 3,13 & 3,28 & 3,79 \\
\hline mais de 1 S.M. & 2,05 & 2,18 & 2,26 & 2,47 & 2,11 & 2,42 & 1,87 & 1,84 & 2,05 & 2,21 \\
\hline URBANO & & & & & & & & & & \\
\hline até $1 / 4$ S.M. & 7,27 & 5,79 & 7,84 & 6,32 & 6,77 & 6,56 & 7,39 & 5,48 & 7,12 & 5,41 \\
\hline $1 / 4$ a $1 / 2$ S.M. & 4,78 & 5,13 & 4,88 & 4,95 & 5,51 & 5,12 & 4,57 & 4,69 & 4,88 & 5,67 \\
\hline $1 / 2$ a 1 S.M. & 3,19 & 3,53 & 2,97 & 3,29 & 2,30 & 3,23 & 3,04 & 3,13 & 3,33 & 3,85 \\
\hline mais de 1 S.M. & 2,01 & 2,15 & 2,16 & 2,42 & 2,33 & 2,37 & 1,85 & 1,82 & 2,04 & 2,20 \\
\hline RURAL & & & & & & & & & & \\
\hline até 1/4 S.M. & 8,83 & 7,44 & 9,58 & 7,78 & 7,93 & 7,06 & 9,70 & 6,82 & 7,89 & 7,10 \\
\hline $1 / 4$ a $1 / 2$ S.M. & 4,31 & 5,02 & 4,41 & 4,95 & 3,94 & 4,97 & 5,35 & 4,48 & 3,81 & 5,32 \\
\hline 1/2 a 1 S.M. & 2,65 & 3,29 & 2,83 & 3,12 & - & 3,44 & 3,12 & 3,32 & 2,49 & 3,34 \\
\hline mais de 1 S.M. & 2,34 & 2,61 & 2,70 & 2,77 & - & 2,84 & 3,04 & 2,54 & 2,01 & 2,43 \\
\hline
\end{tabular}

Fonte: IBGE - Tabulações Especiais dos Censos Demográficos 1970 - 1980 in Oliveira, L.A.P., 1984 
Ressalta-se que a proporção da população econômicamente ativa (PEA) percebendo até um salário mínimo, no Brasil, em 1980, é de $34,2 \%$; no Sudeste este número caiu para $22,7 \%$ enquanto que $11,7 \%$ em 1980 , no Brasil e $15,5 \%$ no Sudeste do país recebiam mais de 05 salários mínimos. São entretanto majoritários os contingentes de baixa remuneração: $64,5 \%$ da PEA no Brasil e $56 \%$ no Sudeste, em 1980, recebiam até 2 salários mínimos (Oliveira, 1984).

Convém destacar que está havendo um crescente aumento da participação da mulher e da criança no mercado de trabalho, bem como acentuado crescimento do número de horas semanais de trabalho para garantir a sobrevivência da familia. Há também um aumento crescente de número de pessoas ingressando no mercado informal da economia.

As importantes mudanças quantitativas e qualitativas nas atividades são expressas tanto pela procura de técnicos e especialistas de nível médio e superior como pela procura de força de trabalho assalariado de baixa remuneração no mercado. Esse último, em função do processo migratório, tem acelerado o aumento considerável de excedentes populacionais, principalmente para a população de baixa renda, influindo nos padrões de comportamento social e demográfico da população.

Outro fator a ser considerado, embora pouco significativo, não só pela omissão das informaçốes estatísticas como pelo fato de ter-se mantido relativamente estável, é a percentagem de mulheres solteiras (37\%).

\section{A GRANDE IMPORTÂNCIA DOS ABORTOS E DO USO DE METODOS ANTICONCEPCIONAIS, INTERFERINDO NA QUEDA DA FECUNDIDADE}

Algumas pesquisas têm demonstrado que a taxa de aborto é bastante alta. Deve-se, entretanto, esclarecer que o movimento pró liberação do aborto tem sido grande, pois que, por ocorrer o mesmo de forma clandestina, os riscos para as mulheres são bastante graves.

Estudos feitos com informações obtidas em hospitais não revelam a intensidade da ocorrência, posto que $o$ atendimento se restringe à chamada gestação de alto risco e a problemas que necessitam de atendimento imediato por terem ocorrido complicações e infecções pós-aborto.
Trabalho realizado em 1965 em São Paulo, tendo por base pesquisa direta, demonstrou que o índice de aborto por 100 gestações era de 17,9 em mulheres casadas - inclusive uniões consensuais - 15-49 anos (Berquó, 1977).

Já no Rio Grande do Norte, o mesmo índice, com informações para 1980, apresentou resultados de 8,7 (Rodrigues e outros, 1982). Esta última informação deve ser vista com certo cuidado por tratar-se de pesquisa elaborada pela BEMFAM (Sociedade Civil BemEstar Familiar no Brasil), orgão financiado por organismos internacionais de planejamento familiar, e que trabalha com base em informações de mulheres vinculadas ao controle para planejamento.

A disseminação acentuada do uso da pílula anticoncepcional, que ocorreu em 1965 no Brasil, possibilitou a difusão de seu consumo por toda a população e em todas as classes de renda, inclusive nas áreas rurais.

Acresce-se ao uso dos meios anticoncepcionais o aumento considerável da esterilização feminina. Este último tem atingido de forma mais intensa a população feminina, com nível mais baixo de instrução.

Camargo sintetiza muito bem a postura ambígüa do governo brasileiro do ponto de vista das políticas populacionais. Se de um lado o Governo mantinha a postura natalista, de ocupação de grandes espaços vazios, especialmente após o golpe de 1964, sob o autoritarismo militar, de outro, as atitudes demonstram a tendência controlista.

Em 1974, na Conferência de Bucareste, "a delegação brasileira já aceitava a liberdade de informação e a decisão dos casais a respeito do número desejável de filhos e da utilização dos meios anticoncepcionais". Na década anterior, o país permitiu a atuação da BEMFAM (Associação Brasileira para o Bem Estar Familiar) e de outras instituições menores voltadas para o planejamento familiar. Deve-se deixar bem claro que o objetivo destas instituições é o de controle populacional. Isto se torna bastante evidente quando, na década de 70, a BEMFAM viu-se liberada para estabelecer convênios em vários Estados, especialmente do Nordeste do país, envolvendo instâncias públicas com objetivos de controle populacional (Camargo, 1982). Concluiu-se, portanto, que há uma clara evidência por parte dos po- 
deres públicos em legitimar a implantação de projetos de planejamento familiar com objetivos puramente controlistas, (onde se inclui a esterilização irreversível), deixando de lado o principal aspecto a ser considerado, que é o da decisão do casal em relação a sua prole.

A questão, entretanto, não deve ser colocada em relação ao tamanho da familia ou se a queda da fecundidade no país é um fenômeno político. Na realidade o que deveria ser pensado é a questão da melhor distribuição da renda. Esse é realmente um problema quando se toma consciência de que boa parte da população brasileira recebe menos de um salário mínimo (Salário mínimo mensal em maio de 1993, no país é inferior a 80 dólares).

Vários estudos têm sido feitos com o objetivo de apontar os fatores que explicam a queda acentuada da fecundidade, de modo particular, nas duas últimas décadas, embora as evidências demonstrem que no período 1968-74 houve um efetivo crescimento econômico. Em tese não se explicaria a queda posto que o próprio Nordeste do país assistiu, no período $1960-80$, a uma "taxa anual de crescimento do produto praticamente semelhante ao do Brasil (7,2 e 7,3\%, respectivamente). Apesar de significativo, foi concentrador e insignificante para diminuir os diferenciais acumulados historicamente e elevar substancialmente a qualidade de vida dos estratos mais carentes da população da Região. Portanto, considerando o crescimento da Região apenas razoável, como explicar o notável declínio de $20 \%$ na TFT, sendo $24 \%$ a nível urbano e $10 \%$ a nível rural na última década (70-80)"? (Martine, G. e Camargo, L., 1984, p.108).

O crescimento econômico não seria, portanto, o fator principal a justificar essa tendência de queda da fecundidade e, segundo Carvalho e outros, ela poderia ser atribuída a uma conjugação de fatores, tanto de ordem estrutural - aumento da proletarização -, como de ordem cíclica - queda do padrão de vida de uma grande parte da população (Carvalho e outros, 1984). Neste trabalho os pesquisadores argumentam que esse intenso processo de proletarização teria levado a um crescente aumento dos custos para sua sobrevivência, tais como a necessidade de compra de produtos alimentares que antes eram produzidos por eles, o pagamento da habitação e mesmo de transporte, para não dizer água, luz, etc, etc. Ao mesmo tempo há uma queda relativa dos salários devido ao alto processo inflacionário pelo qual passa o país. Só recentemente há uma tentativa de reposição desses salários. Caso se mantenha esta reposição o trabalhador poderá, a longo prazo, reconquistar seu magro poder de compra que possuía em 1978.

Podemos, portanto, pensar que os fatores acima mencionados, juntamente com aqueles ligados ao aumento do aborto e das práticas anticoncepcionais seriam parte das explicações para essa que acentuada da fecundidade. Para esse último cabe papel de destaque, de um lado através das políticas de população explícitas ou implícitas do Governo e, de outro, dos próprios meios de comunicação, bem como da penetração cada vez mais agressiva das indústrias farmacêuticas, neste setor, no Brasil.

Cabe destacar que a televisão, hoje bastante difundidade e assistida por todas as camadas da população, através da propaganda dos produtos contidos no "mercado das ilusōes", incentiva cada vez mais a compra de mercadorias - as vitrinas, painéis publicitários, etc dão a esperança para aqueles que só podem consumir os produtos na fantasia. Anexam-se a ela os outros meios de comunicação como jornais, revistas, rádio, etc, que transmitem valores que incluem, além do consumismo, propaganda explícita do planejamento familiar onde o ideal da familia é o daquela constituída por uma prole pequena, isto é, de 02 filhos. Nesse sentido, a população tende a construir essa imagem de reprodução em termos de suas próprias estratégias de sobrevivência e de sua reposição enquanto força de trabalho, cuja demanda acaba sendo regulada indenpendentemente de sua vontade (Tabela: Brasil: Resultados Comparativos. População Residente e Taxas Médias Geométricas Anuais de Crescimento, nos Recenseamentos de 1940, 1950, 1960, 1970 e 1980 segundo as Grandes Regiōes e as Unidades da Federação. 
Brasil

RESULTADOS COMPARATIVOS

POPULAÇĀO RESIDENTE E TAXAS MÉDIAS GEOMÉTRICAS ANUAIS DE CRESCIMENTO, NOS RECENSEAMENTOS DE 1940,1950,1960,1970 e 1980 SEGUNDO AS GRANDES REGIŌES E AS UNIDADES DA FEDERAÇÃO

\section{GRANDES REGIÖES \\ Q UNIDADES DA \\ FEDERAÇÃO}

BRASIL

NORTE

Rondônia

Acre

Amazonas

Roraima

Pará

Amapá

NORDESTE

Maranhão
Piauí
Ceará
Rio Grande do Norte
Paraíba
Pernambuco
Alagoas
Fernando de Noronha
Sergipe
Bahia

Bahia

SUDESTE

Minas Gerais

Espiríto Santo

Rio de Janeiro

São Paulo

SUL

Paraná

Santa Catarina

Rio Grande do Sul

CENTRO - OESTE

Mato Grosso do Sul

Mato Grosso

Goiás

Distrito Federal

FONTE: FIBGE

\section{POPULAÇĀO RESIDENTE}

$18 / 09 / 40 \quad 18 / 07 / 50 \quad 12 / 09 / 60 \quad 19 / 09 / 70$

$\begin{array}{llll}41.165 .289 & 51.941 .767 & 70.070 .457 & 93.139 .037\end{array}$

$1.461 .787 \quad 1.834 .185$

2.561 .782

3.603 .860

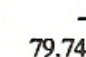

437.268

944.775

37.173
114.788

69.792

158.184

708.459

607.628

17.834

1.119 .790

36.972

1.529 .293

67.750

14.426.185

1.231 .955

816.796

2.092.301

766.516

1.423 .165

2.681.032

950.158

542.579

3.921 .683

18.304.317

6.756 .395

790.420

3.596 .186

7.161.316

7.992 .094

\subsection{7 .838}

1.047 .192

2.706 .611

970.340

1.717 .160

3.395.099

1.094 .845

628

644.255

4.838 .110

22.181 .880

2.469.447

1.242 .136

3.296 .366

1.145 .502

2.000 .851

4.095.379

1.258.107

1.389

752.256

5.920 .447

22.549 .728

30.630 .728

7.797 .133

957.072

4.667.270

9.127.911

5.722 .018

7.835 .418

$1.235 .849 \quad 2.112 .893$

1.177.149

2.112 .893
1.562 .862

4.159 .663

1.250 .98

1.730 .684

235.528

192.531

309.458

211.058

1.209 .368
9.807.657

1.403 .052

6.610 .748

12.809 .231

11.753.075

4.268.239

2.118.116

5.366 .720

2.942 .992

570.291

319.248

1.913.289

140.164
111.064

215.299

955.235

40.885

2.167 .018

114.359

28.111 .927

2.992 .686

1.600 .573

4.361.603

1.550 .244

2.382.617

5.160 .640

1.508 .109

1.241

900.744

7.493 .470

39.853 .498

11.407.415

1.599 .333

8.994 .802

17.771 .948

16.496 .493

6.929 .868

6.664 .891

5.073 .259

997.326

599.764

2.938 .677

537.492
2.901 .734
TAXAS MÉDIAS GEOMÉTRICAS (100 hab)

$19 / 09 / 80 \quad 1940 / 1950 \quad 1950 / 1960 \quad 1960 / 1970 \quad 1970 / 1980$

$\begin{array}{llllll}119.070 .865 & 2.39 & 2.99 & 2.89 & 2.49\end{array}$

5.885 .536

2.33

3.34

3.47

5.03

490.153

3.77

1.427 .784

79.407

3.410 .088

175.442

6.39
-3.20

$1.53 \quad 3.33$

1.33
$-\quad 4.65$

1.74

4.65

34.855 .469

3.27

6.14

4.000 .083

2.138 .790

5.297 .750

1.901 .745

2.769 .521

6.147 .080

1.989 .703

1.323

1.136 .951

9.472 .523

51.746 .318

13.389.605

2.019 .877

11.300 .665

25.036.171

19.038 .935

7.629.405

3.631 .368

7.778 .162

7.544 .607

1.367.197

1.138 .866

3.864 .629

1.173.915 
BRASIL

EVOLUCÃO DA TAXA DE FECUNDIDADE TOTAL

$1950-2020$

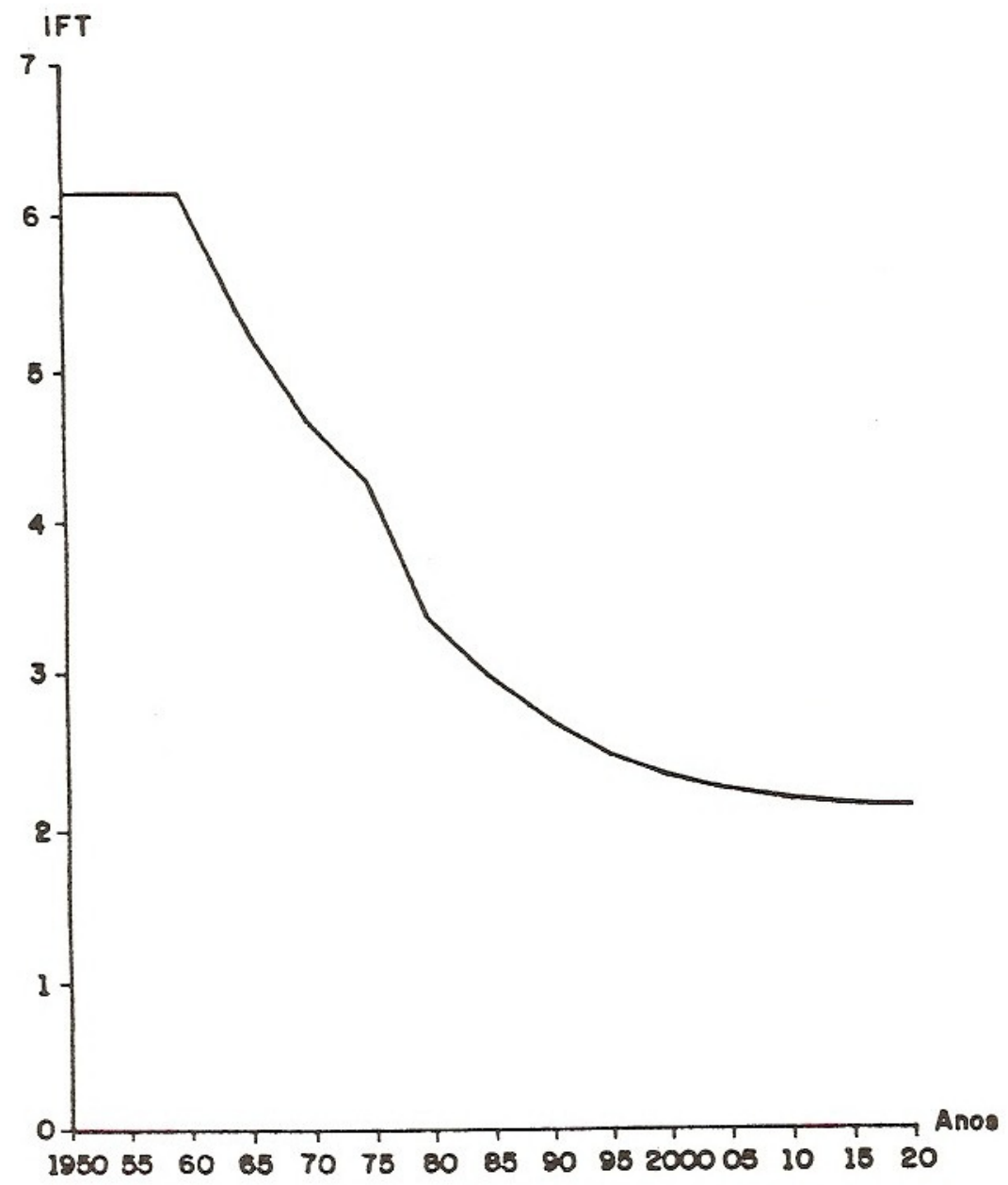

Fonte:

Fundeço Inatituto Bresileiro de Geogrefic - Estatiatica-IBGE; Noupert (1987), in - Fundece̋o SEADE, 1990. 


\section{A transição Demográfica Brasileira e as Repercussões na Estrutura Etária de População}

A tendência à queda acentuadade fecundidade nos últimos anos tem levado os estudiosos da população a reverem suas projeçōes. Calculava-se que no ano 2000 a população brasileira atingiria 200 a 220 milhões de habitantes enquanto que estimativas mais recentes apontam um contingente populacional próximo de 172 milhões de habitantes.

A rapidez com que vem ocorrendo as transformações na dinâmica populacional tem levado a um questinamento às teorias e explicações "clássicas" da transição demográfica.

Embora sejam várias as explicações e interpretações, a teoria da transição demográfica postula mudanças de normas e valores que levam a um esforço de milhōes de pessoas no sentido de controlar sua prole e na consequente queda da fecundidade. Esse esforço, no país, estaria vinculado à acentuados processos de industrialização, urbanização e diferenciação do processo de produção e consumo.

A teoria da transição tem uma validez, de certa forma, insuficiente para o Brasil pois a queda acentuada da fecundidade, conforme já descrito, tem alcance relativo dada as enormes disparidades regionais no quadro econômico e social do país. Nem todos os segmentos da população participaram das vantagens do crescimento nestas últimas décadas e portanto não deveriam, em tese, ter assistido a essa queda acentuada de seus padrões de fecundidade. Parece ter tido grande signifícado a atuação do Estado, o desenvolvimento e interveniência dos meios de comunicação de massa e a disseminação de métodos anticoncepcionais mais modernos e eficazes (Martine, 1984 - Fundação SEADE, 1990).

De forma bastante sintética pode-se dizer que a primeira etapa da transição demográfica - a natalidade permanece alta e a mortalidade inicia um descenso parece ter ocorrido até o final da década de 60 deste século.

De 1940 a 1960 a estrutura etária da população brasileira não se alterou praticamente quando os menores de 15 anos correspondiam a cerca de $43 \%$, os de 15 a 59 anos $52 \%$ e os de 60 anos ou mais $5 \%$ (Fundação SEADE, 1990).
A partir de 1960 a queda acentuada da fecundidade que apresentava em média 6 filhos por mulher passando no final da década para 5 filhos, incidindo basicamente no grupo etário de 0 a 4 anos no censo de 1970, e com diminuição das taxas de mortalidade levam a concluir que o que ocorreu entre 1940 e 1960 poderia ser definido como o final do que seria a primeira etapa da transição demográfica.

A esperança de vida ao nascer no período de 1940 a 60 teve ganho de 15 anos.

A segunda etapa - a mortalidade continua a cair e a natalidade inicia uma fase decrescente - se torna mais evidente a partir da década de 1960.

Será a partir do final deste século que as alteraçōes demográficas ocorrerão de forma mais intensa quando a pirâmide etária apresentar os resultados dessa acentuada queda da fecundidade ocorrida a partir da década de 60 fazendo prever que a população de mais de 60 anos alcance o percentual de $15,1 \%$ da população do Brasil.

Cerca de 20 anos após o início da acentuação da queda da fecundidade o número médio de filhos por mulheres reduziu-se de 6,1 para 3,5 em 1984, podendo ser considerado como uma das quedas mais elevadas do mundo. O grupo etário de $0-14$ anos que em 1970 representava aproximadamente $42 \%$ da população diminuiu para 38,3\% em 1980 enquanto que os adultos e idosos aumentaram. Segundo estimativas para o ano 2000 será o grupo de 15 a 59 anos que absorverá a perda relativa do grupo jovem chegando a $62 \%$ (Fundação SEADE, 1990).

O início da terceira etapa - a mortalidade e a natalidade se aproximam em níveis consideravelmente mais baixos - só deverá ocorrer após a metade do próximo século quando as taxas seriam em torno de zero, pois as estimativas apontam para 2020/25 uma taxa bruta de natalidade em torno de 16 por mil e de mortalidade por volta de 8 por mil o que significaria um crescimento populacional baixo.

No caso da mortalidade esta diminuição tem sua explicação fundamentalmente na melhoria dos sistema de saneamento básico. A partir de 1940 os progressos da medicina permitiram melhor controle das doenças infecciosas. A descoberta do DDT e outros inseticidas 
permitiram melhor controle dos insetos vetores das doenças. Acrescente-se ainda as alterações na política de saúde e o crescimento da política previdenciária.

Desta forma infere-se que a rápida queda da mortalidade vincula-se mais aos fatores anteriormente relacionados do que a transformação da sua organização social onde as disparidades regionais e sociais refletem, em grande medida, os padrões de concentração da renda (Martine, Camargo - 1984), (F́undação SEADE 1990).

Dentre os fatores que atuaram na queda da fecundidade não resta dúvida que foram fundamentais para as mudanças no comportamento reprodutivo por camada social o que se vincula ao acesso aos meios de controle e a decisão dos casais a respeito do tamanho da prole. Alguns estudiosos consideram também que o processo de proletarização teria aumentado o custo de subsistência de força de trabalho com a substituição de bens de consumo produzidos de forma doméstica por outros obtidos no mercado e a introdução de gastos anteriormente não consumidos tais como habitação, transporte, energia elétrica etc. Com repercussões na queda do padrão de vida (Martine e Camargo, 1984).

As mudanças no padrão reprodutivo da população brasileira redundam em alterações na composição etária. É inquestionável o envelhecimento da população do país com tendência de acentuação.

Esse envelhecimento a nível regional vincula-se não só ao comportamento das variáveis, mortalidade e fecundidade, mas também à migração interna. Essa últi- ma tem enorme significação na conformação etária da população pois que é esse um fenômeno bastante seletivo quanto aos grupos etários.

Segundo o censo de $1980,40 \%$ da população brasileira morava fora de seu município de nascimento. Mais de $50 \%$ estava na faixa de 15 a 40 anos, assim a migração tende a rejuvenecer as áreas de destino ao mesmo tempo em que promove um envelhecimento nas áreas de saída.

\section{A TENDENCIA DOS FATOS DEIXA-NOS ENTREVER O FUTURO}

As modicações na estrutura etária devido às alterações tanto no comportamento reprodutivo da população, como pela diminuição da mortalidade e pela migração interna acarreta uma série de implicações para o planejamento do social.

A medida em que a população envelhece o custo global do seguro social tende a aumentar ao mesmo tempo em que vai exigir maior atendimento para as doenças cardiovasculares e congênitas e menor investimento no setor de obstetrícia, ginecologia e puericultura. Reduz também o ritmo de construções escolares modificando o perfil das necessidades de educação ( $\mathrm{Ta}$ bela: Brasil - Evolução da População, Taxa de Crescimento Anual e Distribuição Etária - 1900 - 2025; Figuras: Brasil: Evolução da Taxa de Fecundidade Total 1950-2020); Brasil: Estrutura Etária da População 1940-2025; . 


\section{BRASIL}

\section{ESTRUTURA ETÁRIA DA POPULACÃO $1940-2025$}
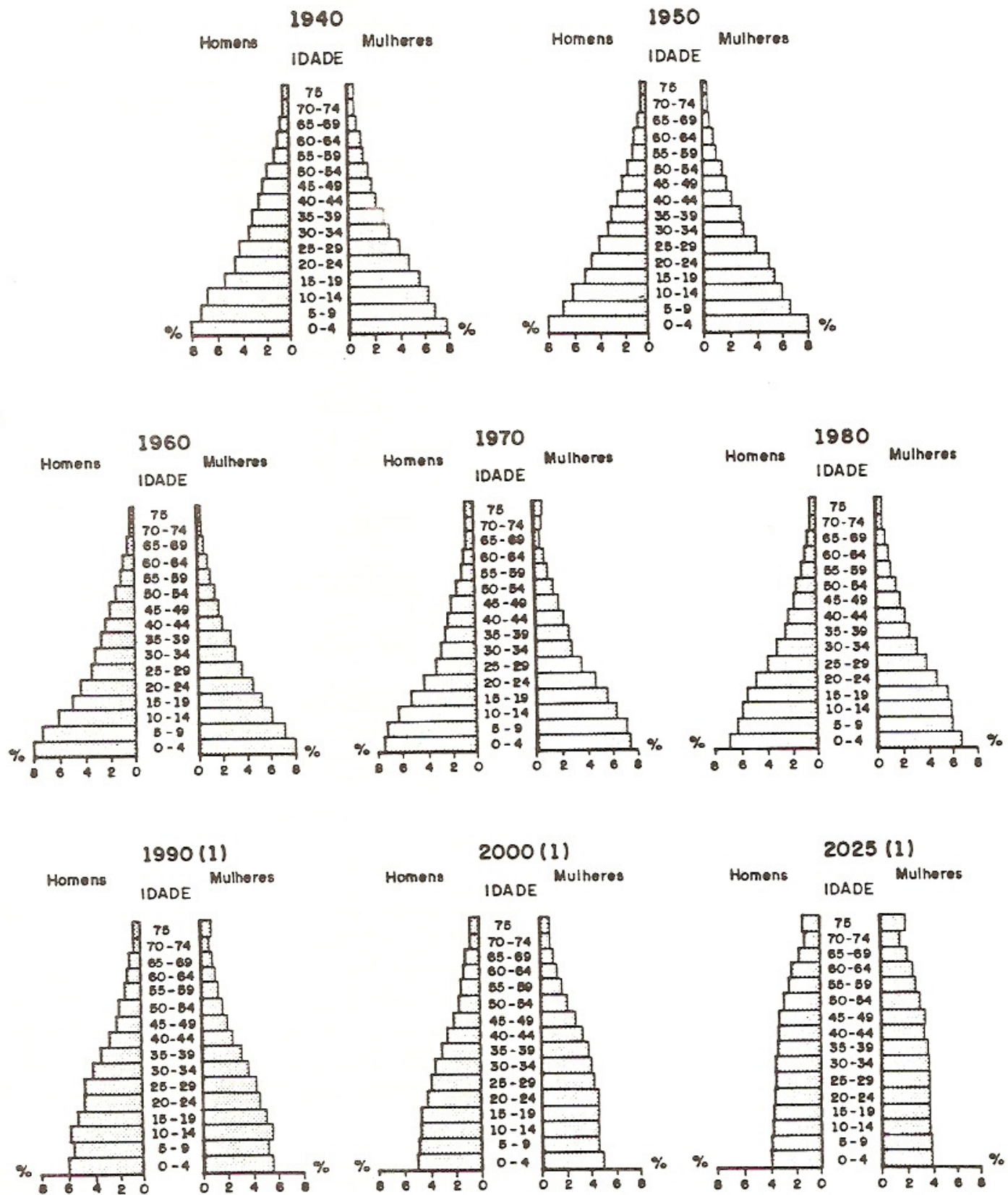

Fonte: Fundaçōo Instifuto Brosileiro de Geografio e Estatístico - IBGE - Censos Demogróficos Neupert (1987). in Fundaç̋ిo SEADE, 1990.

(1) Estimativa 


\section{EVOLUÇÃO DA POPULAÇÃO, TAXA DE CRESCIMENTO ANUAL E DISTRIBUIÇÃO ETÁRIA $1900-2025$}

\begin{tabular}{|c|c|c|c|c|c|}
\hline \multirow[b]{2}{*}{ Anos } & \multirow{2}{*}{$\begin{array}{c}\text { População } \\
\text { (Em } 1.000 \text { hab) }\end{array}$} & \multirow{2}{*}{$\begin{array}{c}\text { Taxa de } \\
\text { Crescimento } \\
\text { Anual } \\
(\%)\end{array}$} & \multicolumn{3}{|c|}{ Distribuição Etária (\%) } \\
\hline & & & $\begin{array}{l}0 \text { a } 14 \\
\text { Anos }\end{array}$ & $\begin{array}{c}15 \text { a } 59 \\
\text { Anos }\end{array}$ & $\begin{array}{l}60 \text { Anos } \\
\text { e Mais }\end{array}$ \\
\hline $1900 \ldots$ & 18.200 & 2,1 & 44,4 & 52,3 & 3,3 \\
\hline $1920 \ldots$. & $27.500(1)$ & 2,0 & 42,8 & 53,2 & 4,0 \\
\hline $1940 \ldots$. & $41.236(1)$ & 2,4 & 42,5 & 53,4 & 4,1 \\
\hline $1950 \ldots$ & 51.944 & 3,0 & 41,9 & 53,9 & 4,2 \\
\hline $1960 \ldots$. & 70.119 & 2,9 & 42,7 & 52,6 & 4,7 \\
\hline $1970 \ldots$. & 93.139 & 2,5 & 42,1 & 52,8 & 5,1 \\
\hline $1980 \ldots$. & 119.099 & 2,1 & 38,2 & 55,7 & 6,1 \\
\hline $1990 \ldots$. & $147.291(2)$ & 1,6 & 33,8 & 59,1 & 7,1 \\
\hline $2000 \ldots$ & $172.403(2)$ & 1,3 & 29,5 & 62,2 & 8,3 \\
\hline $2010 \ldots$ & $195.469(2)$ & 1,0 & 26,3 & 63,7 & 10,0 \\
\hline $2025 \ldots .$. & $225.253(2)$ & & 22,9 & 62,0 & 15,1 \\
\hline
\end{tabular}

Fonte: Fundação Instituto Brasileiro de Geografia e Estatística - IBGE; Neupert (1987).
(1) Dado retificado pelo IBGE
(2) População estimada.

Diminui a carga de dependência ao mesmo tempo em que se amplia o contingente da força de trabalho. A carga de dependência dos idosos é mais lenta e menos significativa embora o Estado deva pensar em atendimento específico a esta faixa fato que só agora no Brasil começa de forma incipiente a se pensar (Fundação SEADE, 1990; Martine e Camargo, 1984; Rossini, 1988).

$O$ aumento do contingente na força de trabalho não elimina a necessidade de atenção à saúde da população brasileira devido às deficências crônicas de nutrição. Há que se pensar numa avaliação da estrutura produtiva para a própria organização social e econômica do país, pois de nada adiantaria aumentar a proporção da população na força de trabalho se o Estado não criar condições de geração de empregos e de preparo técnico profissional para enfrentar a modernidade que os tempos exigem.

O significado de uma população maior ou menor, de um ritmo de crescimento mais lento ou mais acelerado para o desenvolvimento do país e para a manutenção de uma boa qualidade de vida da sociedade não pode se ater, de forma isolada, dentro de uma perspectiva apenas populacional. 
Uma política de população implica em um nível de abrangência muito maior por parte do Estado onde a distribuição espacial desta população deveria ocupar lugar de destaque. A articulação das atividades econômicas sobre o espaço constitui no fator precípuo do planejamento.
Não resta dúvida que o planejamento da prole terá e deverá ser sempre um direito do cidadão e não uma decisão do Estado. A fome continuará a existir enquanto não houver melhor distribuição da renda qualquer que seja a taxa de crescimento populacional.

\section{BIBLIOGRAFIA}

ANDRADE, Manuel C. de - 1982 - Redistribuicão da População e das Atividades Econômicas no Espaço Brasileiro". in Anais do 3o. Encontro Nacional ABEP. Associação Brasileira de Estudos Populacionais. Aguas de Săo Pedro, S.P., p. 195-206.

GRAHAM, Douglas H. e HOLANDA Fo, Sergio Buarque de 1980. As migrações Inter-Regionais e Urbanas e o Crescimento Econômico do Brasil. in Migraçäo Interna: Textos Selecionados. Tomo 2. Banco do Nordeste do Brasil S.A.. Fortaleza.

JATENE, H. da S. - 1983 - Reabertura da fronteira sob controle: A colonização particular Dirigida na Amazonia. 4o. Encontro Nacional de Geografia Agrária. Universidade Federal de Uberlândia, M.G..

MARTINE, G. - 1981 - Notas sobre os resultados preliminares do censo demográfico de 1980.14 p. (mimeo).

MARTINE, G. e CAMARGO, L - 1984 - Crescimento y distribuição da população brasileira: Tendências recentes. in Revista Brasileira de Estudos Populacionais. Ano 1, no. 1, p. 94-144.

MARTINS, J.S. - 1980 - Expropriação e Violência (a questão geopolítica no campo) Coleção Ciências Sociais. Hucitec. São Paulo.

NEUPERT, R. F. - 1987 - Nova projeção da populaçăo brasileira: hipóteses baseadas em informações recentes. in Wong, L. R. (org.) et al. Futuro da População Brasileira: projeçōes, previsôes e técnicas. Embu, ABEP.
OLIVEIRA, L.A.P. - 1984 - A dinâmica demográfica đa Região Sudeste e seus determinantes. in 4o. Encontro Nacional de Estudos Populacionais. ABEP. São Paulo, p. 1-62.

RODRIGUES, W. e outros - 1984 - Pesquisa sobre saúde materno-infantil e planejamento familiar. RG do Norte. 1980. Rio de Janeiro, -BENFAM.

ROSSINI, Rosa Ester - 1988 - Geografia e Gênero-La mulher na lavoura canavieira Paulista. Tese de Livre Docência-USP, São Paulo.

ROSSINI, Rosa Ester - 1987 - Dinâmica Atual do Processo Migratório no Brasil. Emigrazione Europee e Papolo Brasiliano. Roma. Centro Studi Emigrazione. p. 403-422.

SINGER, P. - 1975 - Economia Política da Urbanização. Editora Brasiliense. CEBRAP. São Paulo.

Fundação Sistema Estadual de Análise de Dados (SP) - 1990 - O Idoso na Grande São Paulo. Funđação SEADE. São Paulo.

TASCHNER, S.P., e BOGUS, L.M. - 1986 - Mobilidade Espacial da População Brasileira: Aspectos e Tendências. in Revista Brasileira de Estudos Populacionais. vol. 3, no. 2, Julho/dez. 1986, p. 87-111.

TASCHNER, S.P. e BOGUS, L.M. - 1984 - Redistribuiçăo Espacial e fluxos migratórios nos anos 70. in Anais do 4o. Encontro da ABEP. Aguas de São Pedro. S.P., 1715-1742. 